\title{
Sertoli Cells Improve Myogenic Differentiation, Reduce Fibrogenic Markers, and Induce Utrophin Expression in Human DMD Myoblasts
}

\author{
Laura Salvadori ${ }^{1,2,+}$, Sara Chiappalupi ${ }^{2,3,4,+}$, Iva Arato ${ }^{3}$, Francesca Mancuso ${ }^{3}$, Mario Calvitti ${ }^{3}$, \\ Maria Cristina Marchetti ${ }^{3}$, Francesca Riuzzi ${ }^{2,3,4} \oplus^{\infty}$, Riccardo Calafiore ${ }^{3,5}$, Giovanni Luca ${ }^{3,5,6, *}$ \\ and Guglielmo Sorci $2,3,4,5,6, * \mathbb{D}$
}

\section{check for} updates

Citation: Salvadori, L.; Chiappalupi, S.; Arato, I.; Mancuso, F.; Calvitti, M.; Marchetti, M.C.; Riuzzi, F.; Calafiore, R.; Luca, G.; Sorci, G. Sertoli Cells Improve Myogenic Differentiation, Reduce Fibrogenic Markers, and Induce Utrophin Expression in Human DMD Myoblasts. Biomolecules 2021, 11, 1504. https://doi.org/ 10.3390/biom11101504

Academic Editor: Jingsong Zhou

Received: 15 July 2021

Accepted: 8 October 2021

Published: 12 October 2021

Publisher's Note: MDPI stays neutral with regard to jurisdictional claims in published maps and institutional affiliations.

Copyright: (c) 2021 by the authors. Licensee MDPI, Basel, Switzerland. This article is an open access article distributed under the terms and conditions of the Creative Commons Attribution (CC BY) license (https:/ / creativecommons.org/licenses/by/ $4.0 /)$.
1 Department of Translational Medicine, University of Piemonte Orientale, 28100 Novara, Italy; laura.salvadori@uniupo.it

2 Interuniversity Institute of Myology (IIM), 06132 Perugia, Italy; sarac.chiappalupi@gmail.com (S.C.); francesca.riuzzi@unipg.it (F.R.)

3 Department of Medicine and Surgery, University of Perugia, 06132 Perugia, Italy; iva.arato@libero.it (I.A.); francesca.mancuso@unipg.it (F.M.); mario.calvitti@unipg.it (M.C.); maria.marchetti@unipg.it (M.C.M.); riccardo.calafiore@unipg.it (R.C.)

4 Consorzio Interuniversitario Biotecnologie (CIB), 34127 Trieste, Italy

5 Centro Biotecnologico Internazionale di Ricerca Traslazionale ad Indirizzo Endocrino, Metabolico ed Embrio-Riproduttivo (CIRTEMER), 06132 Perugia, Italy

6 Centro Universitario di Ricerca sulla Genomica Funzionale (CURGeF), 06132 Perugia, Italy

* Correspondence: giovanni.luca@unipg.it (G.L.); guglielmo.sorci@unipg.it (G.S.); Tel.: +39-07-5585-8231 (G.L.); +39-07-5585-8258 (G.S.)

$+\quad$ These authors contributed equally.

Abstract: Duchenne muscular dystrophy (DMD) is an X-linked disease caused by mutations in $D M D$ gene translating in lack of functional dystrophin and resulting in susceptibility of myofibers to rupture during contraction. Inflammation and fibrosis are critical hallmarks of DMD muscles, which undergo progressive degeneration leading to loss of independent ambulation in childhood and death by early adulthood. We reported that intraperitoneal injection of microencapsulated Sertoli cells $(\mathrm{SeC})$ in dystrophic mice translates into recovery of muscle morphology and performance thanks to anti-inflammatory effects and induction of the dystrophin paralogue, utrophin at the muscle level, opening new avenues in the treatment of DMD. The aim of this study is to obtain information about the direct effects of $\mathrm{SeC}$ on myoblasts/myotubes, as a necessary step in view of a translational application of SeC-based approaches to DMD. We show that (i) SeC-derived factors stimulate cell proliferation in the early phase of differentiation in $\mathrm{C} 2 \mathrm{C} 12$, and human healthy and DMD myoblasts; (ii) SeC delay the expression of differentiation markers in the early phase nevertheless stimulating terminal differentiation in DMD myoblasts; (iii) SeC restrain the fibrogenic potential of fibroblasts, and inhibit myoblast-myofibroblast transdifferentiation; and, (iv) $\mathrm{SeC}$ provide functional replacement of dystrophin in preformed DMD myotubes regardless of the mutation by inducing heregulin $\beta 1 /$ ErbB2/ERK1/2-dependent utrophin expression. Altogether, these results show that SeC are endowed with promyogenic and antifibrotic effects on dystrophic myoblasts, further supporting their potential use in the treatment of DMD patients. Our data also suggest that SeC-based approaches might be useful in improving the early phase of muscle regeneration, during which myoblasts have to adequately proliferate to replace the damaged muscle mass.

Keywords: duchenne muscular dystrophy (DMD); Sertoli cell; utrophin; heregulin $\beta 1$; myoblast differentiation; fibrosis; myofibroblast transdifferentiation

\section{Introduction}

Duchenne muscular dystrophy (DMD) is a recessive $X$-linked lethal disease affecting one over 3600-5000 live male births [1,2]. DMD is due to mutations in the dystrophin 
gene $(D M D)$ leading to lack of a functional protein and subsequent inability to recruit the dystrophin-associated protein complex (DAPC) at the sarcolemma resulting in susceptibility of myofibers to rupture during contraction [3]. Muscles of DMD patients or experimental models of DMD show progressive necrosis of the myofibers, chronic inflammation, and reactive regeneration, which lead to exhaustion of muscle precursor cell pool and replacement of myofibers with fibrous and fatty tissues [3,4]. Inflammation and fibrosis are the most critical hallmarks of DMD muscles, responsible of the onset and the progression of the pathology [5,6]. DMD patients experience loss of independent ambulation by their teenage years, and die in the early adulthood due to cardiac and respiratory failure [3,7]. A wide spectrum of therapeutic approaches to DMD have been explored in the last decades and many of them are currently under clinical evaluation, although several limitations, such as unsatisfying muscle recovery, the need for immunosuppression, and relevant adverse effects encourage for further investigation [8-10]. The standard therapy to DMD still remains the use of glucocorticoids despite their limited efficacy and undesired side effects [10].

We set up a therapeutic approach [11,12] based on the peculiar properties of Sertoli cells (SeC), a cell type of the seminiferous tubules of the testis in which they favor the maturation of developing germ cells and protect them against the host immune system [13]. Besides creating a physical barrier (the blood-testis barrier), SeC secrete a plethora of trophic and immunomodulatory factors that confer to these cells the ability to survive long time after engraftment, and protect allo- and xenogenic engraftments of tissues and organs [14-16]. SeC isolated from specific pathogens free (SPF) pre-pubertal pigs were encapsulated in highly biocompatible alginate-based microcapsules (MC-SeC) and injected into the peritoneal cavity of $m d x$ mice, an experimental model of DMD, in the absence of pharmacological immunosuppression [11,12]. A single injection of MC-SeC resulted in amelioration of muscle morphology and performance as a consequence of the secretion by $\mathrm{SeC}$, from the peritoneal cavity into the bloodstream, of anti-inflammatory factors and heregulin $\beta 1$, an inducer of the dystrophin paralogue, utrophin. Short- and longterm beneficial effects of $\mathrm{MC}-\mathrm{SeC}$ treatment (i.e., reduction of inflammatory infiltrate, re-expression of utrophin at the sarcolemma, and reduced necrosis of myofibers) have been reported in several muscles, including the diaphragm, thus opening new perspectives in the treatment of DMD [11,12]. Here, we have investigated the effects of SeC on muscle precursor cells, with particular regards to human healthy and DMD myoblasts/myotubes as a necessary step in view of a potential application of SeC-based treatments to DMD.

\section{Materials and Methods}

A detailed Key resources table (Table A1) is reported in Appendix A.

\subsection{Sertoli Cell Isolation, Purification, and Characterization}

$\mathrm{SeC}$ were isolated from testes of Large White neonatal pigs, according to established methods modified in our laboratory [12,17]. Briefly, after removal of the fibrous capsule the testes were finely chopped and digested enzymatically with a solution of trypsin and DNase I followed by digestion with collagenase P. The pellet was passed through a 500-mm stainless steel mesh and resuspended in glycine to eliminate residual Leydig and peritubular cells. The resulting SeC were cultured in HAM'S F12 supplemented with $0.166 \mathrm{nM}$ retinoic acid and 1\% Insulin-Transferrin-Selenium (ITS) + Premix in 95\% air/5\% $\mathrm{CO}_{2}$ at $37^{\circ} \mathrm{C}$. Detection of anti-Müllerian hormone (AMH, unique prepubertal SeC marker), insulin-like3 (INSL3, Leydig cells marker), alpha-smooth muscle actin (ASMA, peritubular cells marker), and protein gene product 9.5 (PGP9.5, gonocyte and spermatogonial cells marker) were performed $[12,17]$.

\subsection{Sertoli Cell-Conditioned Medium}

SeC were seeded in complete medium composed of HAM'S F12 supplemented with $0.166 \mathrm{nM}$ retinoic acid and 1\% of Insulin-Transferrin-Selenium (ITS) + Premix. After 
3 days of culture, complete medium was replaced with high-glucose Dulbecco's modified Eagle's medium (HG-DMEM) supplemented with $100 \mathrm{U} / \mathrm{mL}$ penicillin and $100 \mathrm{mg} / \mathrm{mL}$ streptomycin $(\mathrm{P} / \mathrm{S})$ without any other nutritional sources $\left(1 \mathrm{~mL} / 1.0 \times 10^{6} \mathrm{SeC}\right)$ for $72 \mathrm{~h}$. Thereafter, SeC-conditioned medium was collected and centrifuged at $2500 \times \mathrm{g} 30 \mathrm{~min}$ to discard cell debris. The supernatant was recovered and added with $2 \%$ horse serum (HS) to obtain SeC-conditioned differentiation medium (SeC-DM). Unconditioned differentiation medium (U-DM) was obtained using the same procedure in the absence of SeC. Freshlyprepared SeC-DM or U-DM were used in experiments with C2C12 myoblasts.

\subsection{Cell Culture}

Murine C2C12 myoblasts (CRL-1772) and human WI-38 fibroblasts (CCL-75), obtained from the American Type Culture Collection (Manassas, VA, USA), were cultured in growth medium composed of HG-DMEM supplemented with $20 \%$ fetal bovine serum (FBS) and $\mathrm{P} / \mathrm{S}$. C2C12 myoblasts were seeded $2.9 \times 10^{4}$ cells $/ \mathrm{cm}^{2}$, cultured for $24 \mathrm{~h}$ in GM, and then shifted to SeC-DM or U-DM for the indicated times. Where indicated, myoblasts were cultured in SeC-DM or U-DM in the presence of TGF (transforming growth factor)$\beta(5 \mathrm{ng} / \mathrm{mL})$ for $24 \mathrm{~h}$ in order to induce myoblast-myofibroblast transdifferentiation. Human healthy and DMD primary myoblasts were obtained from Telethon Network of Genetic Biobanks and the Myobank-AFM of the Institut de Myologie. Human myoblasts were cultured in Skeletal Muscle Cell Growth Medium (Promo Cell) supplemented with $15 \% \mathrm{FBS}$ and P/S. To obtain myotubes, myoblasts were seeded $2.9 \times 10^{4}$ cells $/ \mathrm{cm}^{2}$ in growth medium and, after $24 \mathrm{~h}$, switched to HG-DMEM supplemented with 5\% HS, insulin $(10 \mu \mathrm{g} / \mathrm{mL})$, apotransferrin $(100 \mu \mathrm{g} / \mathrm{mL})$, gentamicin sulfate $(50 \mu \mathrm{g} / \mathrm{mL})$, and L-Glutamine (1\%) (human differentiation medium, huDM). WI-38 fibroblasts or human myoblasts or myotubes were co-cultured in the absence or presence of freshly isolated $\mathrm{SeC}$ $\left(2.0 \times 10^{5} \mathrm{SeC} / \mathrm{mL}\right)$ as indicated by the use of transwells (pores $0.4 \mu \mathrm{m}$, Falcon). In some experiments, human DMD myotubes were co-cultured with or without $\mathrm{SeC}$ in the absence or presence of anti-heregulin $1 \beta$ blocking antibody $(2 \mu \mathrm{g} / \mathrm{mL})$ or the same amounts of non-immune IgG added to the upper chamber of the transwells for $48 \mathrm{~h}$. Human DMD myotubes pretreated with the ErbB receptor tyrosine kinase inhibitor, PD158780 (100 nM), or vehicle (DMSO) for $20 \mathrm{~min}$ were cultured in SeC-DM or U-DM in the absence or presence of PD158780 for additional $24 \mathrm{~h}$. Cells were maintained in a humidified atmosphere containing $5 \% \mathrm{CO}_{2}$ at $37^{\circ} \mathrm{C}$.

\subsection{May-Grünwald/Giemsa Staining and Morphometric Evaluations}

Fusion indexes, total nuclei and nuclei/myotube ratios were determined after MayGrünwald/Giemsa staining, as reported [17,18]. Briefly, C2C12 and human primary myoblasts were fixed in cold absolute methanol for $8 \mathrm{~min}$ and stained with May-Grünwald. After $3 \mathrm{~min}$, Sorensen's phosphate buffer ( $0.067 \mathrm{M}, \mathrm{pH}$ 6.8) was added for $4 \mathrm{~min}$. Cells were then stained with Giemsa solution diluted in Sorensen's phosphate buffer 1:10 for $12 \mathrm{~min}$. Cells were dried and observed with an Olympus BX51 microscope (Olympus, Milan, Italy). Evaluations were performed on cells acquired at $10 \times$ magnification in five randomly selected fields/well using Image J software (ImageJ v1.8.0_172, National Institutes of Health, USA). The fusion indexes were calculated as the percentages of nuclei inside myotubes (i.e., syncytia containing at least three nuclei) versus the total number of nuclei.

Myotube diameters were measured after immunofluorescence for myosin heavy chain (MyHC)-II (see paragraph 2.5), as described [18]. Briefly, 10 randomly chosen fields of MyHC-II stained images were acquired at $20 \times$ magnification for each condition and three different measurements were performed along the longitudinal axis of each myotube using Image J software. Results were expressed as percentages of average myotube diameters with respect to control myotubes. 


\subsection{Immunofluorescence}

Human myoblasts were seeded on glass coverslips pretreated with gelatin, and cocultured with or without $\mathrm{SeC}$ for $48 \mathrm{~h}$. Myoblasts were fixed in cold absolute methanol for $8 \mathrm{~min}$ and permeabilized for $10 \mathrm{~min}$ with $0.4 \%$ Triton X-100 in phosphate-buffered saline (PBS). Then, samples were treated with blocking buffer (BB; $3 \%$ bovine serum albumin (BSA) and $1 \%$ glycine in PBS) for $1 \mathrm{~h}$, and incubated overnight (O.N.) at $4{ }^{\circ} \mathrm{C}$ with an antiutrophin (1:10) or anti- $\alpha$-dystroglycan (1:20) primary antibody in 3\% BSA in PBS. The day after, samples were washed with $0.01 \%$ Tween-20 in PBS (T-PBS) and incubated with an antimouse Alexa Fluor 594-conjugated antibody diluted 1:100 in 3\% BSA in PBS for $1 \mathrm{~h}$. Nuclei were counterstained with $4^{\prime}, 6$-diamidino-2-phenylindole (DAPI). Immunofluorescence for MyHC-II was performed to evaluate myotube diameters, as described [19]. For 5-bromo-2'deoxyuridine (BrdU) staining, $\mathrm{C} 2 \mathrm{C} 12$ myoblasts were seeded on pretreated glass coverslips $1.3 \times 10^{4}$ cells $/ \mathrm{cm}^{2}$ and the day after switched to U-DM or SeC-DM. After $24 \mathrm{~h}$, BrdU $(10 \mu \mathrm{M})$ was added for $1 \mathrm{~h}$, and the cells were fixed in cold absolute methanol for $10 \mathrm{~min}$ and permeabilized for $5 \mathrm{~min}$ with $0.1 \%$ Triton X-100 in PBS. Samples were incubated with hydrochloric acid $(\mathrm{HCl}, 2 \mathrm{~N})$ for $30 \mathrm{~min}$ and washed with borate buffer $(0.1 \mathrm{M}, \mathrm{pH} 8.3)$ followed by PBS, before incubation with an anti-BrdU primary antibody (1:50) in 3\% BSA in PBS for $1 \mathrm{~h}$ at room temperature (RT). After washes in T-PBS and PBS, samples were incubated with the secondary anti-mouse Alexa Fluor 488-conjugated antibody (1:100 in T-PBS) for $1 \mathrm{~h}$ at RT. Nuclei were counterstained with DAPI. Samples were mounted with fluorescent mounting medium and viewed by an epifluorescence microscope (Leica DMRB, Milan, Italy) equipped with a digital camera.

\subsection{Western Blotting}

Cells were lysed in protein extraction buffer, and equal amounts of total protein extract $(30 \mu \mathrm{g})$ were resolved by SDS-PAGE for Western blotting analysis, as described in [19]. Primary and secondary antibodies used are reported in Appendix B (Table A2).

\subsection{Real-Time PCR}

Total RNA from human primary myoblasts was extracted using TRIsure ${ }^{\mathrm{TM}}$ reagent (Bioline) following the manufacturer's instructions. Reverse-transcription was performed using PrimeScript TM RT reagent kit (Takara Bio Europe, Saint-Germain-en-Laye, France). Real-time PCR analysis was performed on Stratagene Mx3000P using $5 \times$ HOT FIREPol EvaGreen qPCR Mix Plus (ROX) ready-to-use solution (Solis BioDyne, Tartu, Estonia) using the primers reported in Appendix C (Table A3). Calculation was performed with a dedicated software in comparison with a standard gene (GAPDH).

\subsection{Cytofluorimetric Analysis}

Cells were cultured in 6-well plates. After treatment, cells that were floating in the culture medium were harvested, washed with PBS, and added with ipotonic propidium iodide solution (PI; $0.1 \%$ sodium citrate, $0.1 \%$ Triton X-100, and $50 \mathrm{mg} / \mathrm{l}$ propidium iodide). These cells suspended in PI were pooled with the adherent cells in the respective well previously washed with PBS. Reunited cells were incubated with PI for $30 \mathrm{~min}$ at $4{ }^{\circ} \mathrm{C}$. Cell cycle analysis was performed by flow cytometry using fluorescence-activated cell sorting (FACS, Coulter Epics XL-MLC with a beam of light from a $488 \mathrm{~nm}$ argon laser).

The percentages of apoptotic cells were evaluated by an annexin $\mathrm{V} /$ propidium iodidebased commercial kit (Annexin V-FITC apoptosis detection kit; BioVision Inc., Milpitas, CA, USA) following the manufacturer instructions. Briefly, adherent cells were gently trypsinized, washed, and incubated with annexin V-FITC and propidium iodide for $5 \mathrm{~min}$ at RT before being quantified by flow cytometry using FL1 and FL2 signal detectors.

\subsection{DCFH-DA Assay}

The DCFH-DA (dichlorodihydrofluorescein diacetate) method was used to detect intracellular ROS. C2C12 myoblasts were cultured in U-DM or SeC-DM for $24 \mathrm{~h}$, and 
DCFH-DA $(30 \mu \mathrm{M})$ was added to the medium for $30 \mathrm{~min}$ at $37^{\circ} \mathrm{C}$. The fluorescence of $2^{\prime}, 7^{\prime}$-dichlorofluorescein (DCF) was detected (485 nm excitation, $535 \mathrm{~nm}$ emission) using a Titertek Fluoroscan II (Flow Laboratories, McLean, VA, USA).

\subsection{Statistical Analysis}

Quantitative data are presented as means \pm SD (standard deviation) or SEM (standard error of the mean) of at least three independent experiments. Counts were performed by three independent operators blind to the treatments. Representative experiments and images are shown unless stated otherwise. Statistical analysis was performed using twotailed, unpaired $t$ test. $\mathrm{P}$ values lower than 0.05 were considered statistically significant. Statistical data were processed by IBM $^{\circledR}$ SPSS $^{\circledR}$ Statistics Version 18 software (IBM, Armonk, NY, USA).

\section{Results}

\subsection{SeC Stimulate Myoblast Proliferation without Affecting the Myogenic Potential}

The direct effects of SeC on myoblasts have never been reported so far. C2C12 myoblasts cultured in growth medium (GM) were switched to unconditioned (U-DM) or SeC-conditioned (SeC-DM) differentiation medium for different times. After $24 \mathrm{~h}$, myoblasts cultured in SeC-DM showed increased cell numbers in comparison with control myoblasts, as observed by inverted phase contrast microscopy (Figure 1A) and evaluated by cell count (Figure 1B), suggesting that SeC-released factors increase cell proliferation and/or reduce cell death. Indeed, the BrdU incorporation assay showed a $~ 65 \%$ increase in the percentage of BrdU-positive (i.e., replicating) cells (Figure 1C), and cytofluorimetric analysis after annexin $\mathrm{V} /$ propidium iodide staining showed a concomitant $\sim 53 \%$ reduction in the apoptotic extent (Figure 1D), in the presence of SeC-DM compared with U-DM. Moreover, differentiating myoblasts cultured with SeC-DM were characterized by reduced oxidative stress since we found $45.0 \pm 14 \%$ reduction in DCF fluorescence relative intensity, which is a measure of intracellular production of reactive oxygen species (ROS), compared with control myoblasts (Figure 1E).

Apoptotic events increase physiologically during the myogenic differentiation process, serving the critical function of removing excess myoblasts and limiting muscle mass [20]. Thus, we evaluated myoblast cultures at $72 \mathrm{~h}$ in DM by cytofluorimetric analysis and we found again a reduced ( $41 \%$ reduction) apoptosis extent (Figure $2 \mathrm{~A})$ together with a strong reduction $(\sim 65 \%)$ of cells in the $S$ phase in the presence of SeC-DM compared to U-DM (Figure 2B), compatible with a more differentiating cell population. At the same time-point, myoblasts cultured with SeC-DM showed an increased extent of fusion into myotubes, as observed by phase contrast microscopy (Figure 2C) and confirmed by the evaluation of the fusion indexes (i.e., the percentages of nuclei residing in syncytia containing $\geq 3$ nuclei) after May-Grünwald/Giemsa staining (Figure 2D,E). Moreover, at $72 \mathrm{~h}$ the total nuclei/field ratio was increased in the presence of SeC-DM (Figure 2F), in accordance with the stimulated proliferation and the reduced apoptosis extent observed at $24 \mathrm{~h}$ in this condition (Figure 1), and higher numbers of nuclei/myotube were found in SeC-DM compared with U-DM (Figure 2G). Western blot analysis revealed increased amounts of the muscle-specific transcription factor and terminal differentiation marker, myogenin, at $24 \mathrm{~h}$, and increased amounts of the structural protein, myosin heavy chain (MyHC)-II, at $24 \mathrm{~h}$ (when MyHC-II was undetectable in U-DM-cultured myoblasts) and $72 \mathrm{~h}$, in the presence of SeC-DM (Figure $2 \mathrm{H}$ ).

Altogether, these results indicated that factors secreted by SeC stimulate the proliferation of muscle precursor cells and protect them against differentiation-associated apoptosis thus increasing their numbers (Figure 1), and improve their myogenic potential once exposed to differentiating conditions (Figure 2). This was further confirmed by an experiment in which $\mathrm{C} 2 \mathrm{C} 12$ myoblasts were co-cultured with high doses of SeC (microencapsulated $\mathrm{SeC}, \mathrm{MC}-\mathrm{SeC}$ ) for $72 \mathrm{~h}$, resulting in increased cell numbers and almost absence of myotube formation, and then cultured for additional $72 \mathrm{~h}$ after removal of $\mathrm{MC}-\mathrm{SeC}$, resulting in 
a dramatic fusion into myotubes that reached the extent of myoblasts co-cultured with empty microcapsules [17].

A
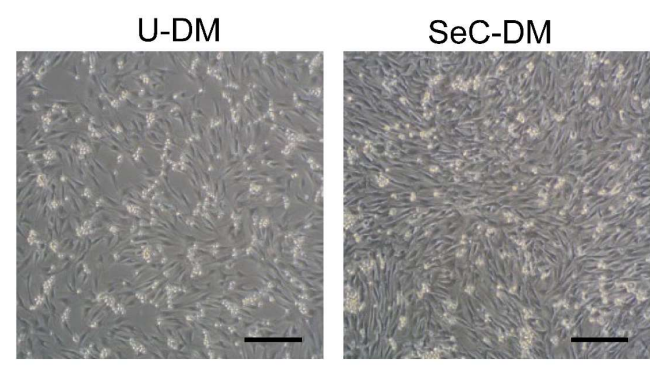

B

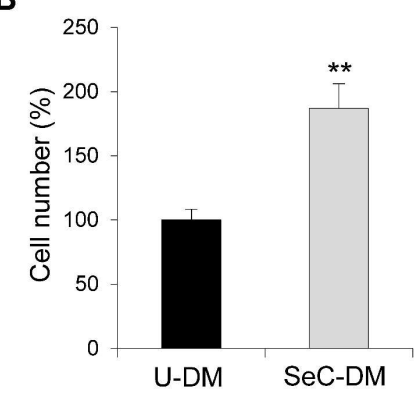

C

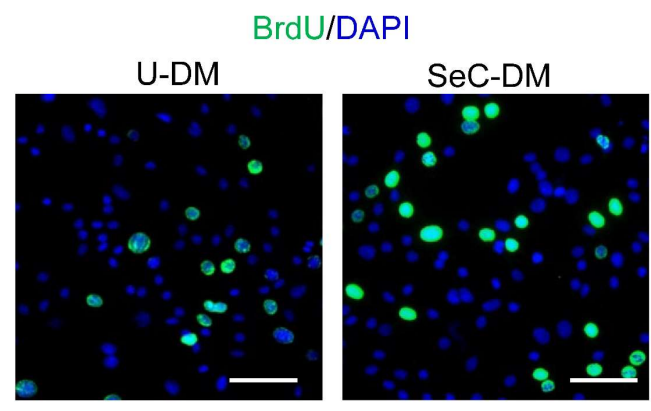

D
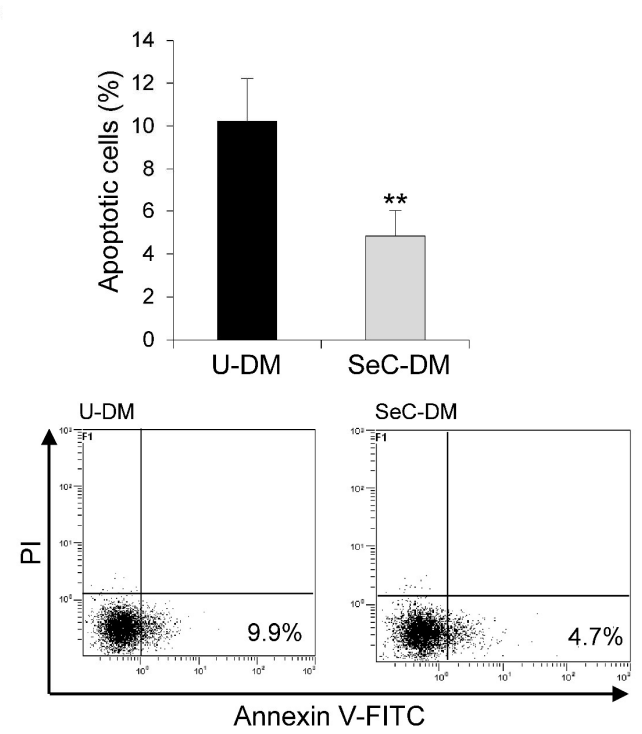

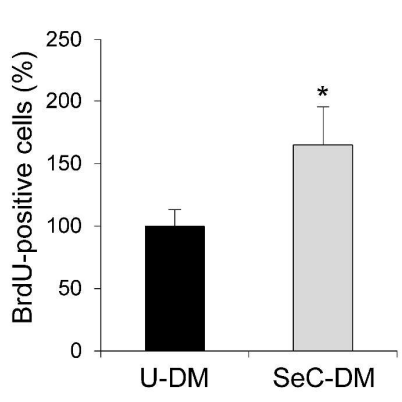

E

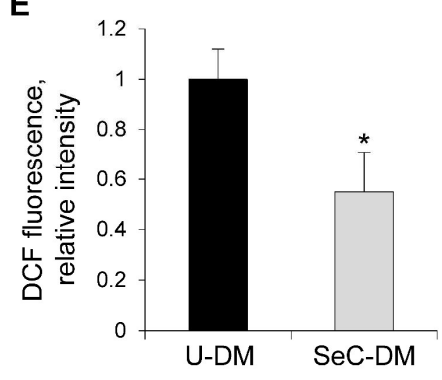

Figure 1. SeC increase $\mathrm{C} 2 \mathrm{C} 12$ myoblast numbers in the early phase of the differentiation process. (A-E) C2C12 myoblasts were cultivated for $24 \mathrm{~h}$ in the presence of unconditioned differentiation medium (U-DM) or DM conditioned by Sertoli cells (SeC-DM). (A) Myoblast cultures were observed by phase contrast microscopy (representative images). (B) Cell count and (C) BrdU assay were performed to evaluate the percentage differences in the number of cells or proliferating cells, respectively. Reported are representative merged images of BrdU (green) and DAPI (blue) used to counterstain nuclei. (D) The percentages of apoptotic cells were determined by FACS analysis after annexin V-FITC and propidium iodide (PI) staining. Representative scatterplots are reported. (E) The $2^{\prime}, 7^{\prime}$-dichlorofluorescein (DCF) fluorescence was measured to evaluate the intracellular levels of reactive oxygen species (ROS). Results are means of three independent experiments ( \pm SD). ${ }^{*}$ and ${ }^{* *}$, significantly different from U-DM $(p<0.05$ and $p<0.01$, respectively). Scale bars, $200 \mu \mathrm{m}(\mathrm{A})$ and $100 \mu \mathrm{m}(\mathbf{C})$. 
A

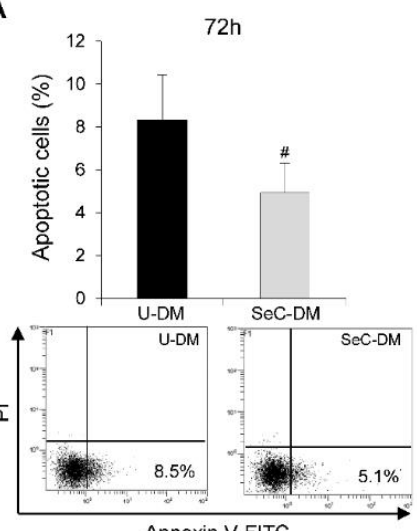

C

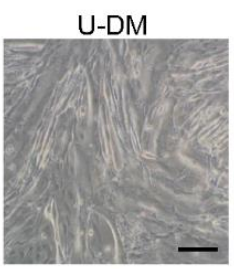

E

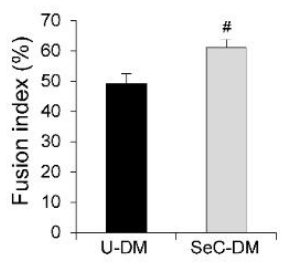

H
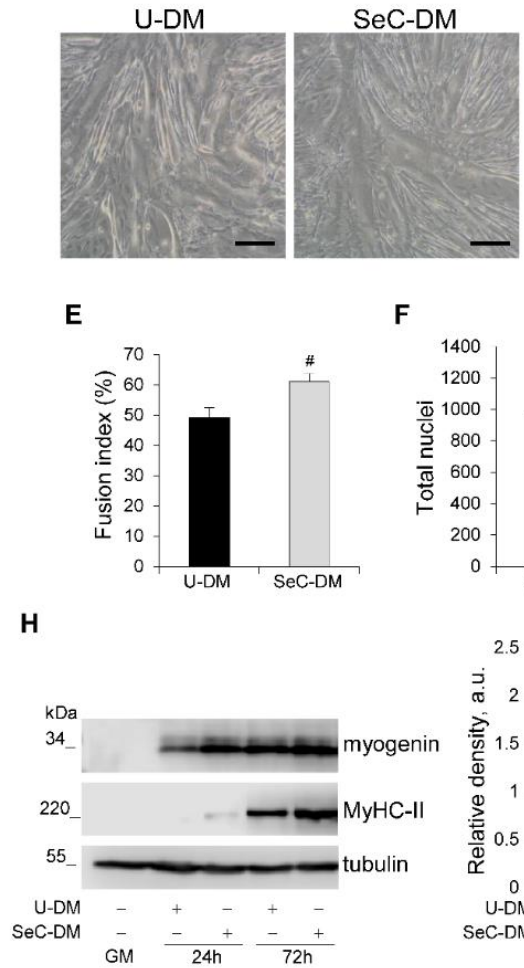
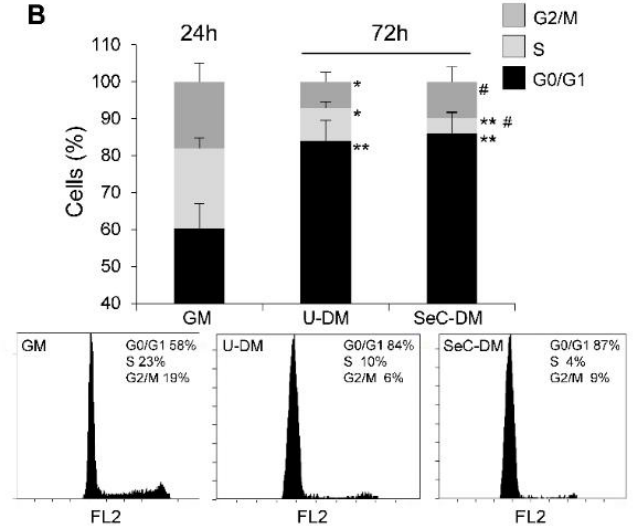

D

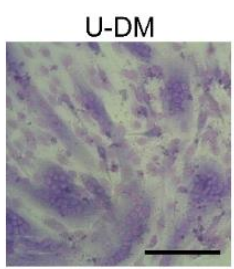

SeC-DM

F
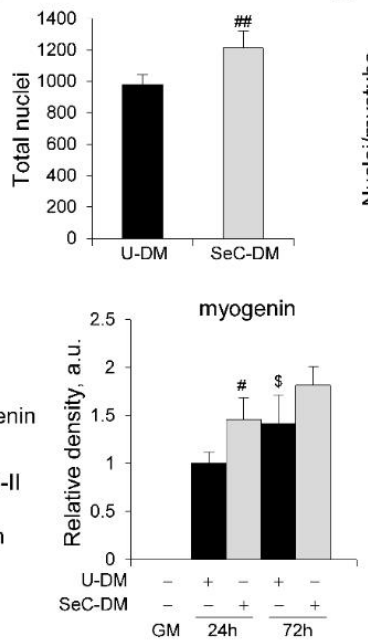

G

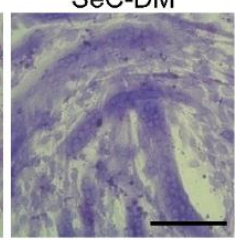

G
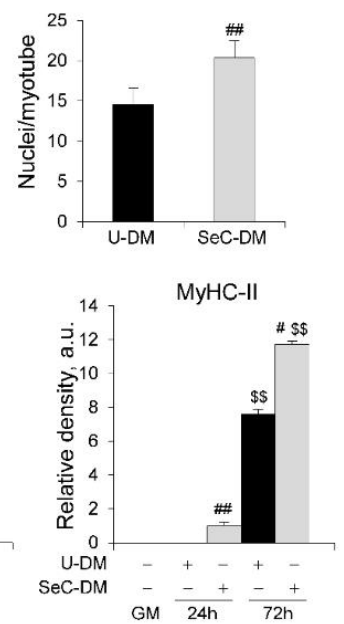

Figure 2. SeC promote myogenic terminal differentiation. (A-G) $\mathrm{C} 2 \mathrm{C} 12$ myoblasts were cultivated either in growth medium (GM) for $24 \mathrm{~h}$ or in unconditioned medium (U-DM) or DM conditioned by Sertoli cells (SeC-DM) for $72 \mathrm{~h}$. FACS analysis was performed to evaluate the percentages of apoptotic cells after annexin V-FITC and propidium iodide (PI) staining at $72 \mathrm{~h}$ in DM. Representative scatterplots are reported (A). The cell cycle in GM (24 h) and DM (72 h) was evaluated by FACS analysis. Representative (B). Reported are representative images of phase contrast microscopy (C) and May-Grünwald/Giemsa staining (D) of myoblasts cultured in U-DM or SeC-DM for $72 \mathrm{~h}$. The fusion indexes (E), the total nuclei/field (F), and the average numbers of nuclei/myotube $(\mathbf{G})$ in myoblasts cultured as in (C,D) were determined. $(\mathbf{H}) \mathrm{C} 2 \mathrm{C} 12$ myoblasts were cultivated either in GM for $24 \mathrm{~h}$ or in U-DM or SeC-DM for $24 \mathrm{~h}$ or $72 \mathrm{~h}$, as indicated. Cells were lysed and the expression of myogenin and myosin heavy chain (MyHC)-II were analyzed by WB. Representative images are shown. The average relative densities of the bands with respect to tubulin bands, used as house-keeping protein, are reported. Results are means \pm SD (A,B) or \pm SEM (E-H) of three independent experiments. * and ${ }^{* *}$, significantly different from GM $(p<0.05$ and $p<0.01$, respectively); \# and \#\#, significantly different from U-DM at the same time-point $(p<0.05$ and $p<0.01$, respectively); $\$$ and $\$$, significantly different from the same treatment at $24 \mathrm{~h}(p<0.05$ and $p<0.01$, respectively). Scale bars (C,D), $200 \mu \mathrm{m}$. 


\subsection{SeC Favor Myotube Elongation and Myosin Heavy Chain Expression in Differentiating DMD Myoblasts}

Therefore, we investigated the effects of SeC on human healthy and DMD myoblasts with different mutations. Human myoblasts derived from muscle biopsies were co-cultured with freshly purified $\mathrm{SeC}\left(2.0 \times 10^{5} \mathrm{SeC} / \mathrm{mL}\right)$ with the use of $0.4 \mu \mathrm{m}$ pore size transwells. Deletion of exons 3-7 (Del3-7) and deletion of exon 51 (Del51) were investigated. At $24 \mathrm{~h}$ in DM, in healthy and DMD myoblasts higher numbers of cells could be seen by inverted phase contrast microscopy in the presence of $\mathrm{SeC}$ compared with control cultures (Figure 3A), which was confirmed by cell counts (increase in cell numbers ranging from 46.7 to $70.0 \%$ ) (Figure 3B). Cytofluorimetric analysis at this time-point showed no significant differences in the apoptosis extents, which were found very low (about 3-5\%) in both healthy and DMD myoblasts irrespective of the presence of $\mathrm{SeC}$ (not shown). The analysis of the cell cycle at $24 \mathrm{~h}$ in DM showed reduced percentages of cells in S and G2/M phases, and increased percentages in G0/G1 phase compared with GM conditions in control healthy and DMD myoblasts, typical of myoblasts entering the differentiation program (Figure 3C). However, co-culture with $\mathrm{SeC}$ for $24 \mathrm{~h}$ in DM translated into increased percentages of cells in $\mathrm{S}$ and G2/M phases, and reduced percentages in G0/G1 phase compared with untreated myoblasts at the same time-point (Figure 3C).

The SeC-dependent increase in cell numbers in healthy and DMD myoblasts was maintained at day 6 in DM, and was particularly evident in Del51 myoblasts, as observed by phase contrast microscopy (Figure S1A) and evaluated by counting the total nuclei after May-Grünwald/Giemsa staining ( 52\% increase in total nuclei in the presence of SeC compared with control) (Figure 4A,B). At this time-point, co-culturing healthy myoblasts with $\mathrm{SeC}$ did not affect apparently the final fusion extent into myotubes, whereas DMD myoblasts seemed have had benefit from the presence of $\mathrm{SeC}$ in terms of myotube formation. Indeed, co-culture with SeC did not affect fusion indexes in healthy myoblasts, and increased fusion indexes in DMD myoblasts, with Del51 showing 54\% increase (Figure 4C). In accordance, at day 6 in DM, DMD, but not healthy myotubes, showed significantly higher nuclei/myotube ratios when co-cultured with SeC ( $69 \%$ increase in the case of Del51) (Figure 4D).

Analysis after immunofluorescence staining for MyHC-II showed similar average myotube diameters in the absence or presence of $\mathrm{SeC}$ in both healthy and DMD myotubes (Figure 4E,F). Together with the increased nuclei/myotube ratios (Figure 4D), this suggests that factors secreted by SeC sustain the longitudinal growth (elongation) in DMD myotubes.

In order to have information about the effects of $\mathrm{SeC}$ on the muscle differentiation process at molecular level, we investigated the expression of the muscle-specific markers, myogenin and MyHC-II. In the presence of SeC, the myogenin amounts were reduced in both healthy and DMD (Del51 and Del3-7) myoblasts at $24 \mathrm{~h}$ and/or $72 \mathrm{~h}$ in DM, and unchanged or increased in healthy and DMD myoblasts, respectively, at 6 days in DM in comparison with the corresponding untreated cells (Figure 5A). A similar expression pattern emerged for MyHC-II, whose expression was delayed until $72 \mathrm{~h}$ in the presence of $\mathrm{SeC}$, and whose amounts were found unchanged or increased at 6 days in healthy and DMD myotubes, respectively (Figure 5A), in accordance with the respective fusion indexes (Figure 4C). This was corroborated by real-time PCR analysis showing lower expression levels of the MyHC-II gene (MYH2) at $72 \mathrm{~h}$ in DM in healthy and Del51 myoblasts cocultured with $\mathrm{SeC}$ (Figure 5B). However, at 6 days in DM MYH2 expression was found unchanged in healthy and dramatically increased in Del51 myoblasts (Figure 5B), in accordance with the detected protein amounts. 
A

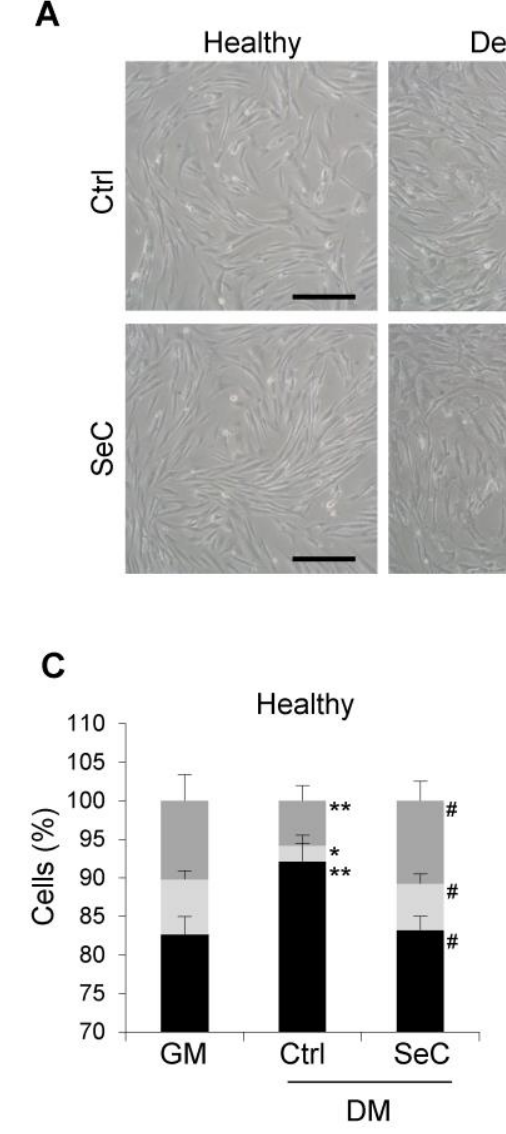

Del3-7
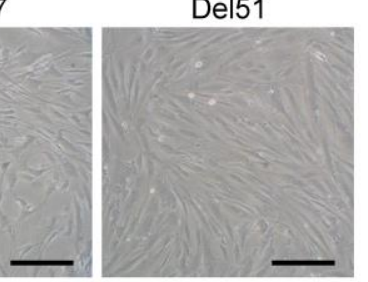

$\triangle \mathrm{S} \square \mathrm{G} 2 / \mathrm{M}$

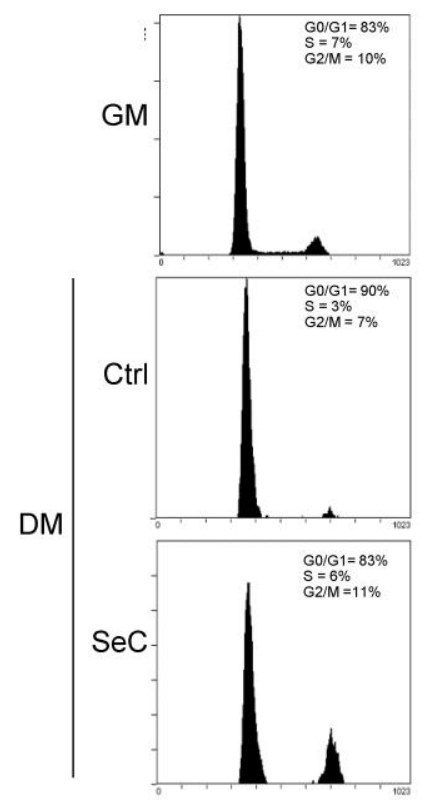

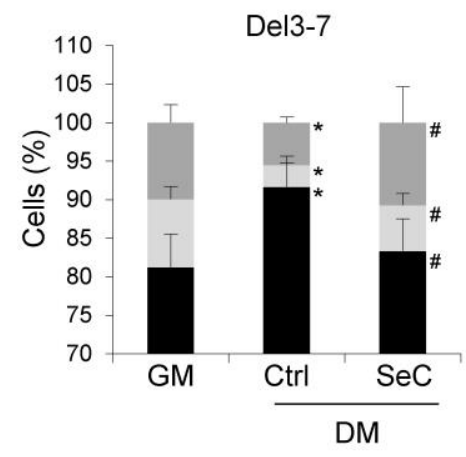

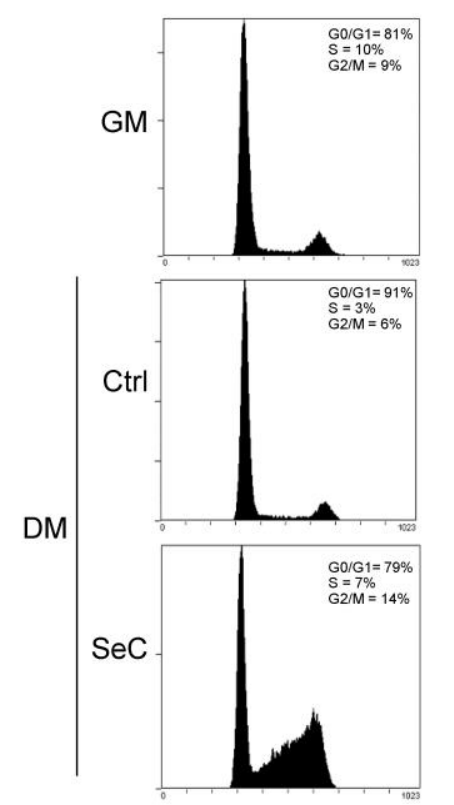

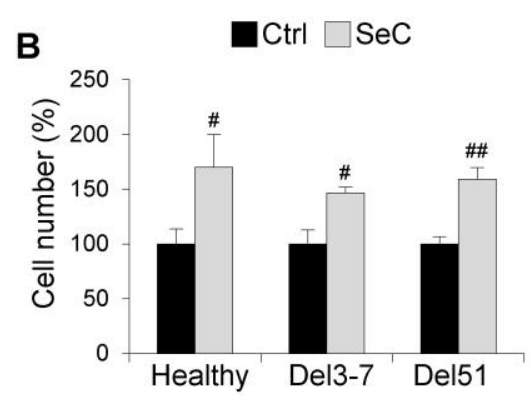
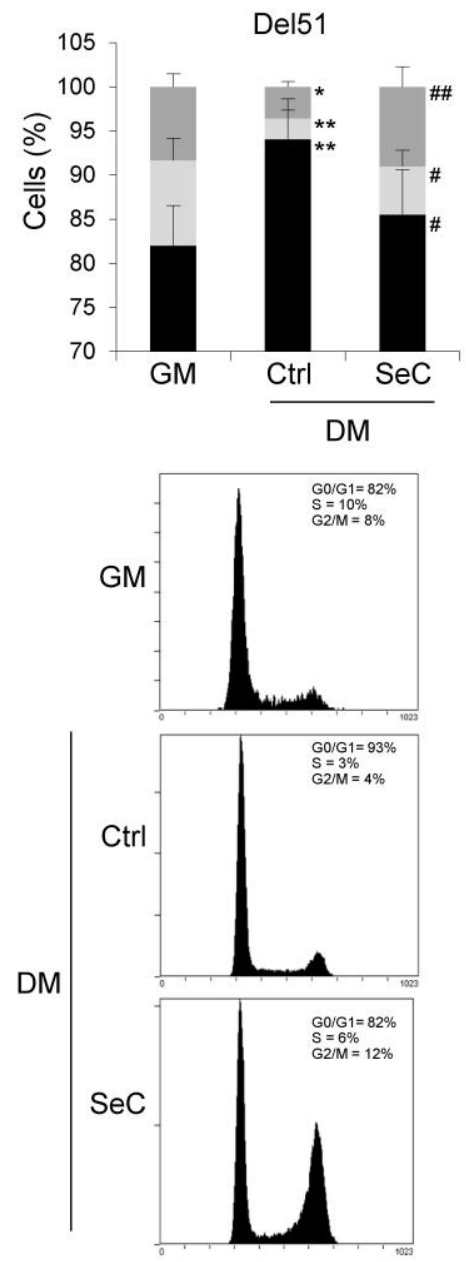

Figure 3. SeC promote cell proliferation in the early phase of the differentiation process in human healthy and DMD myoblasts. (A-C) Human myoblasts derived from healthy donor and DMD (Del3-7 and Del51) patients with different mutations were co-cultured in DM with or without freshly-isolated SeC $\left(2.0 \times 10^{5} \mathrm{SeC} / \mathrm{mL}\right)$ using $0.4 \mu \mathrm{m}$ BD transwells, for $24 \mathrm{~h}$. (A) Reported are representative phase contrast microscopy images. (B) Cell counts were performed to determine the percentage differences in cell numbers. (C) FACS analysis was performed to evaluate the percentages of cells in the different phases of the cell cycle in DM at $24 \mathrm{~h}$ in comparison with untreated cells cultured for $24 \mathrm{~h}$ in GM. Results are means of three independent experiments $( \pm \mathrm{SD})$. ${ }^{*}$ and ${ }^{* *}$, significantly different from GM $(p<0.05$ and $p<0.01$, respectively). \# and \#\#, significantly different from Ctrl $(p<0.05$ and $p<0.01$, respectively). Scale bars (A), $200 \mu \mathrm{m}$. 


\section{A} May-Grünwald/Giemsa
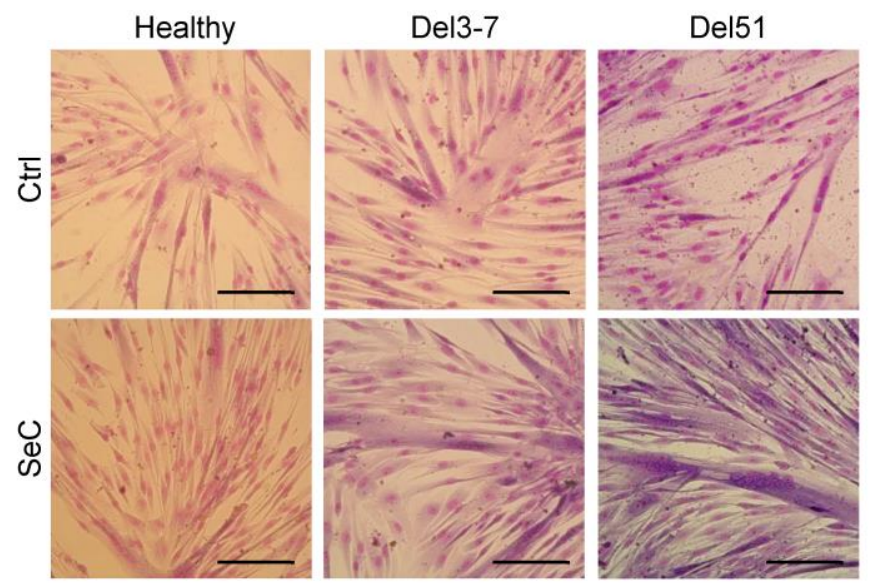

B

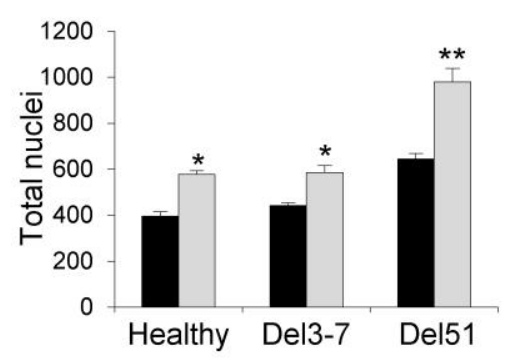

C

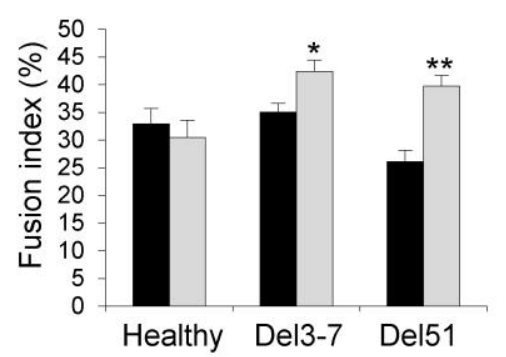

D

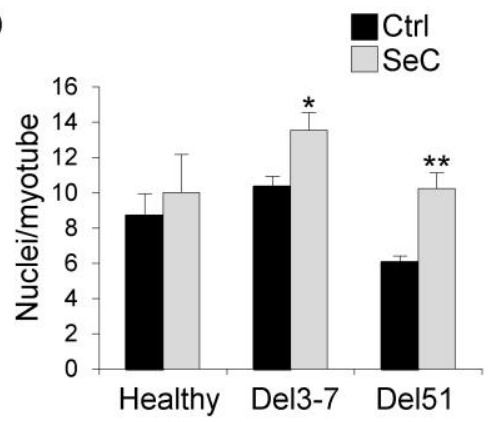

E
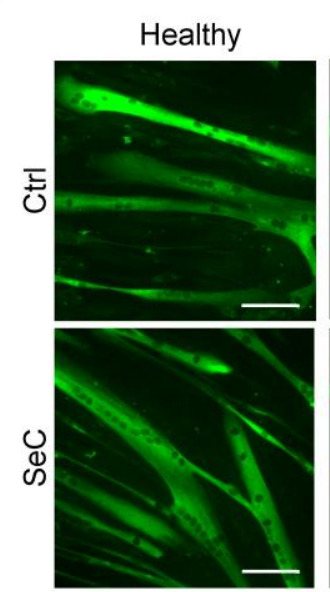

IF, MyHC-II
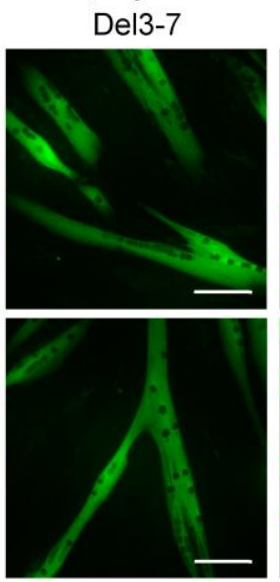

Del51

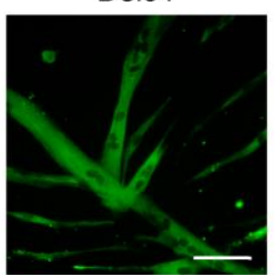

$\mathbf{F}$

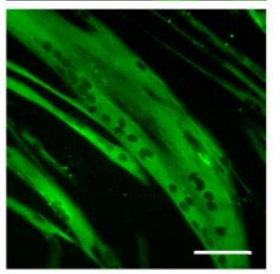

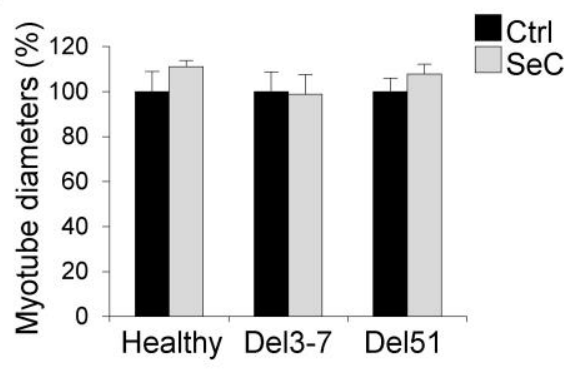

Figure 4. Human DMD myoblasts treated with SeC show improved myogenic differentiation. (A-F) Human myoblasts derived from healthy donor and DMD (Del3-7 and Del51) patients were co-cultured in DM with (SeC) or without (Ctrl) freshly-isolated $\mathrm{SeC}\left(2.0 \times 10^{5} \mathrm{SeC} / \mathrm{mL}\right)$ using $0.4 \mu \mathrm{m} \mathrm{BD}$ transwells, for 6 days. After May-Grünwald/Giemsa staining (A; representative images), the numbers of total nuclei/field (B), the fusion index (C), and the numbers of nuclei/myotube (D) were determined. After immunofluorescence staining for MyHC-II (green) (E; representative images), the percentage changes in myotube diameters were determined $(\mathbf{F})$. Results are means of three independent experiments $( \pm \mathrm{SEM}) .{ }^{*}$ and ${ }^{* *}$, significantly different from internal control (Ctrl) $(p<0.05$ and $p<0.01$, respectively). Scale bars, $200 \mu \mathrm{m}$. 
A
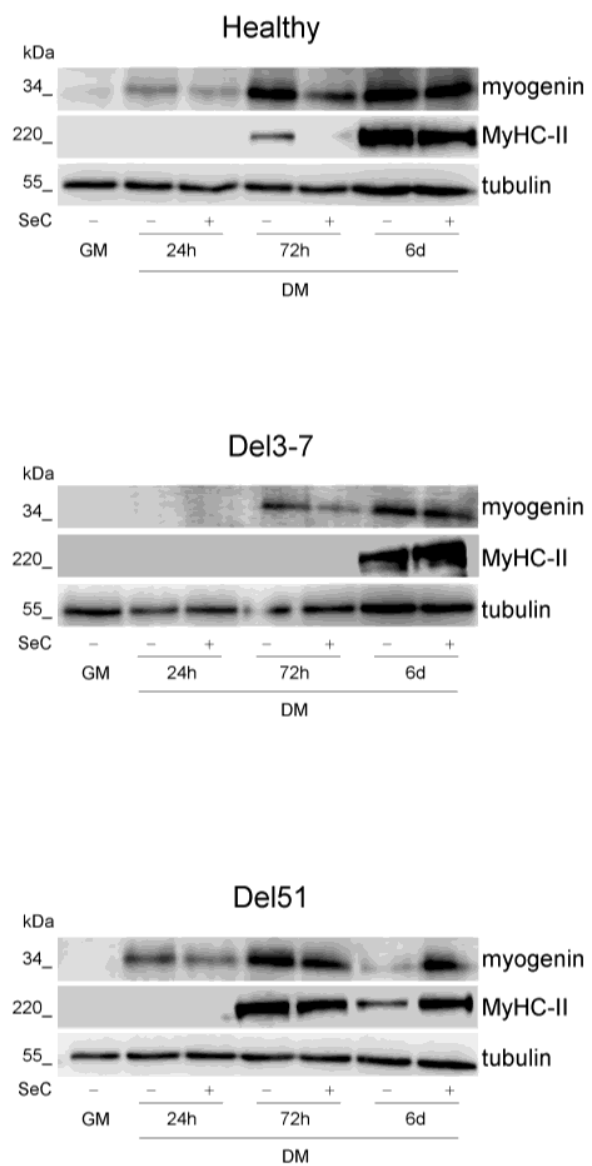

B

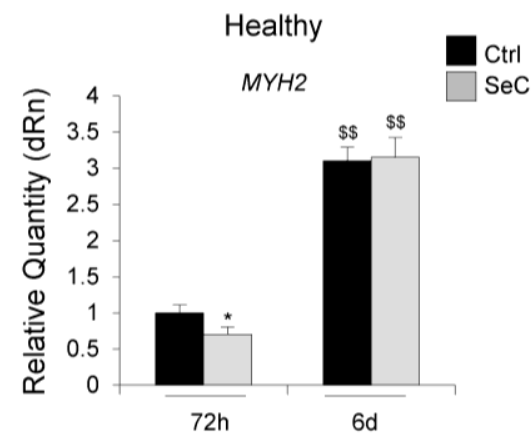

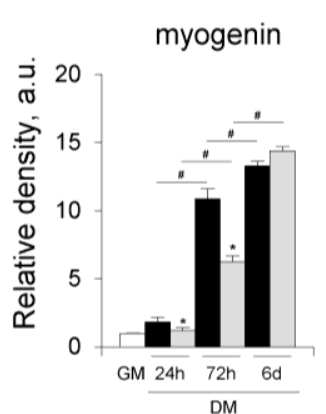
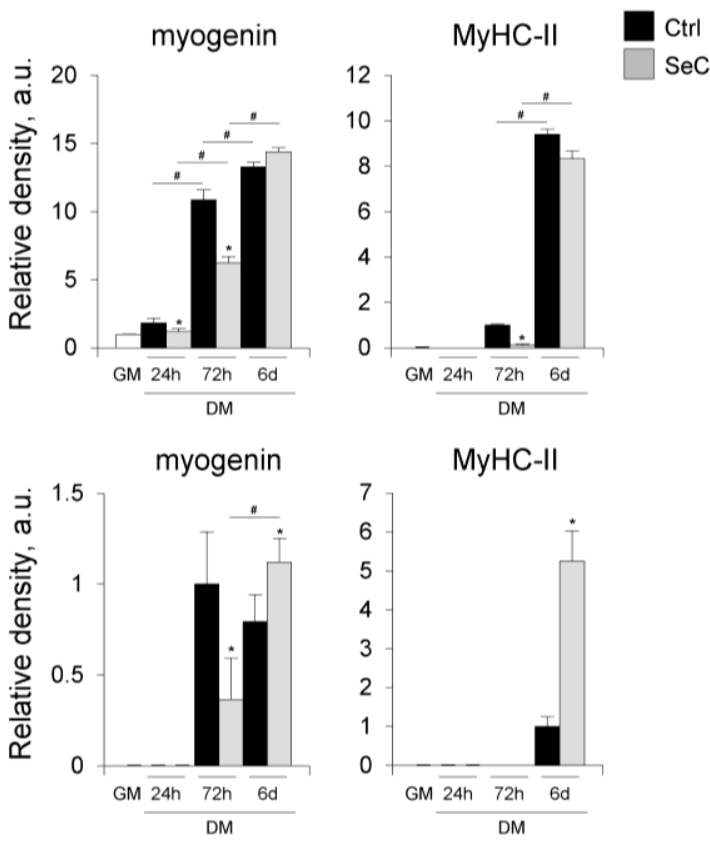

myogenin

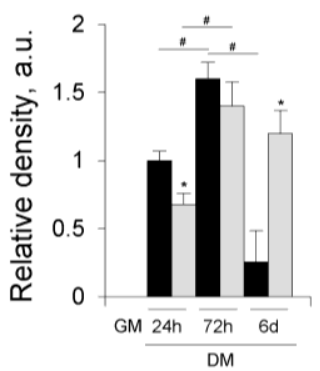

MyHC-II
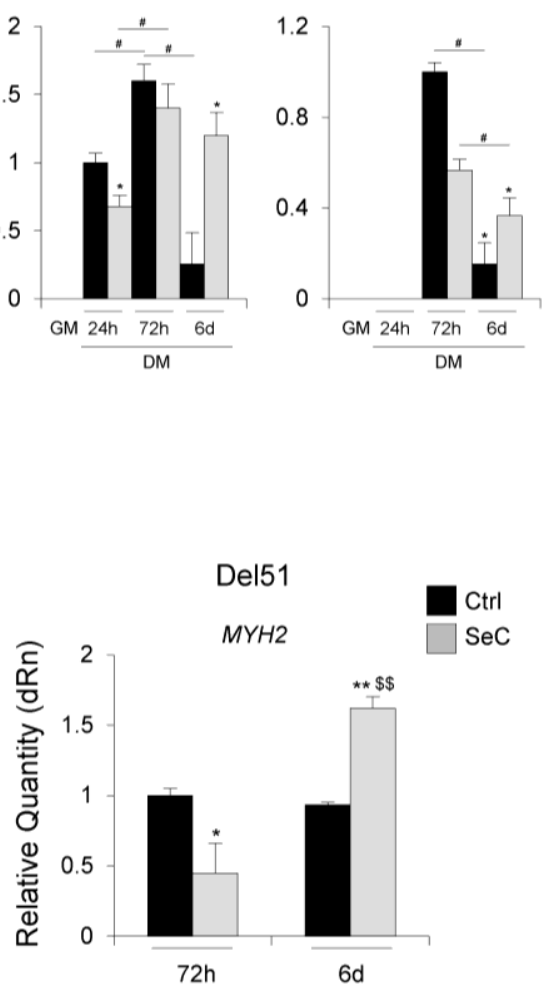

Figure 5. SeC-treated DMD myoblasts show delayed early and improved terminal differentiation. (A,B) Human myoblasts derived from healthy donor and DMD (Del3-7 and Del51) patients were co-cultured in GM for $24 \mathrm{~h}$ or in DM with (SeC) or without (Ctrl) freshly-isolated SeC $\left(2.0 \times 10^{5} \mathrm{SeC} / \mathrm{mL}\right)$ using $0.4 \mu \mathrm{m} \mathrm{BD}$ transwells for $24 \mathrm{~h}, 72 \mathrm{~h}$ or 6 days. (A) Cells were lysed and the expression of myogenin and myosin heavy chain (MyHC)-II were analyzed by WB. Representative images of three independent experiments are reported. The average relative densities $( \pm S D)$ of the bands were determined with respect to tubulin bands, used as house-keeping protein. (B) Real-time PCR analysis for the expression of MYH2 $(\mathrm{MyHC})$ in healthy and Del51 subjects at $72 \mathrm{~h}$ and 6 days. Reported are the means $( \pm \mathrm{SD})$ with respect to control (Ctrl) at $72 \mathrm{~h}$ and normalized for GAPDH used as house-keeping gene. ${ }^{*}$ and ${ }^{* *}$, significantly different from $\mathrm{Ctrl}(p<0.05$ and $p<0.01$, respectively); \#, significantly different $(p<0.05)$; \$\$, significantly different from the same treatment at $72 \mathrm{~h}(p<0.01)$. 
Thus, in DMD myoblasts co-cultured with SeC an early increase in cell numbers occurs that is followed by enhanced differentiation.

\subsection{SeC Restrain the Fibrogenic Potential of Fibroblasts and Inhibit Myoblast- Myofibroblast Transdifferentiation}

DMD muscles are characterized by progressive deposition of fibrotic tissue, which has been linked in part to the transdifferentiation of dystrophic myoblasts into myofibroblasts. Indeed, DMD myoblasts were found to express a more fibrogenic phenotype compared with healthy ones [21]. We found that Del51 myoblasts co-cultured with SeC for 6 days in DM expressed lower levels of the fibrotic markers, COL1A1 (collagen 1A1), FN1 (fibronectin) and CTGF/CCN2 (connective tissue growth factor/cellular communication network factor 2) (Figure 6A), which play a major role in fibrogenesis, suggesting that SeC-secreted factors might inhibit the appearance of the fibrogenic phenotype in DMD muscles. Among the markers tested, CTGF / CCN2 was the only one whose expression was reduced by SeC in Del51 myoblasts already at $72 \mathrm{~h}$ and in healthy myoblasts irrespective of the time-point considered (Figure 6A).

Since myoblast primary cultures are likely to contain a fibroblastic component at different extent, which could mask or concur to the observed effects of $\mathrm{SeC}$ on human myoblasts, we performed experiments with a purified fibroblast cell line. Human WI38 fibroblasts showed significantly reduced expression of the profibrotic genes, COL1A1 and FN1 when co-cultured with $\mathrm{SeC}$ in comparison with control fibroblasts (Figure 6B), indicating a direct effect of $\mathrm{SeC}$ on the fibroblastic component. However, CTGF/CCN2, which was the most downregulated fibrogenic marker in myoblast primary cultures (Figure $6 \mathrm{~A}$ ), resulted not significantly affected by $\mathrm{SeC}$ in fibroblasts (Figure 6B), suggesting a direct effect of $\mathrm{SeC}$ on myoblasts.

To further investigate the role of $\mathrm{SeC}$ in myoblast transdifferentiation, we treated the stabilized myoblast cell line, C2C12, with TGF- $\beta$, which is known to induce transdifferentiation of myoblasts into myofibroblasts [22] and has a major role in inducing fibrosis in DMD muscles [23], in the absence or presence of SeC-DM. We found that SeC-derived factors dramatically hampered the expression of TGF- $\beta$-induced Col1a1, Fn1, Ctgf / Ccn2, and $T g f b 1$ itself (Figure $6 \mathrm{C}$ ).

Thus, SeC appear able to both protect myoblasts against myofibroblast transdifferentiation and restrain the fibrogenic potential of preexisting fibroblasts.

\subsection{SeC Induce Utrophin Expression in DMD Myotubes Regardless of the Mutation}

Previous work demonstrated that $\mathrm{SeC}$ induce the expression of utrophin in murine dystrophic muscles, contributing to the SeC-dependent rescue of muscle morphology and performance [12]. To investigate a similar effect in humans, preformed myotubes obtained from healthy subject or DMD patients (Del51, Del3-7, and G > T transition in the exon 23) were co-cultured with freshly purified SeC. After $48 \mathrm{~h}$, we found an increased expression of utrophin in both healthy and DMD myotubes, ranging from 1.4- to 2.3fold increase compared with untreated controls (Figures 7A and S2A). In accordance, immunofluorescence staining for utrophin revealed a more intense fluorescence signal in myotubes cultured in the presence of $\mathrm{SeC}$, and showed that utrophin was mainly located at the sarcolemma (Figures 7B and S2B). Interestingly, the expression of the member of the utrophin-associated protein complex (UAPC), $\alpha$-dystroglycan was found also increased at the periphery of healthy and DMD myofibers in the presence of SeC (Figure S3). 
A
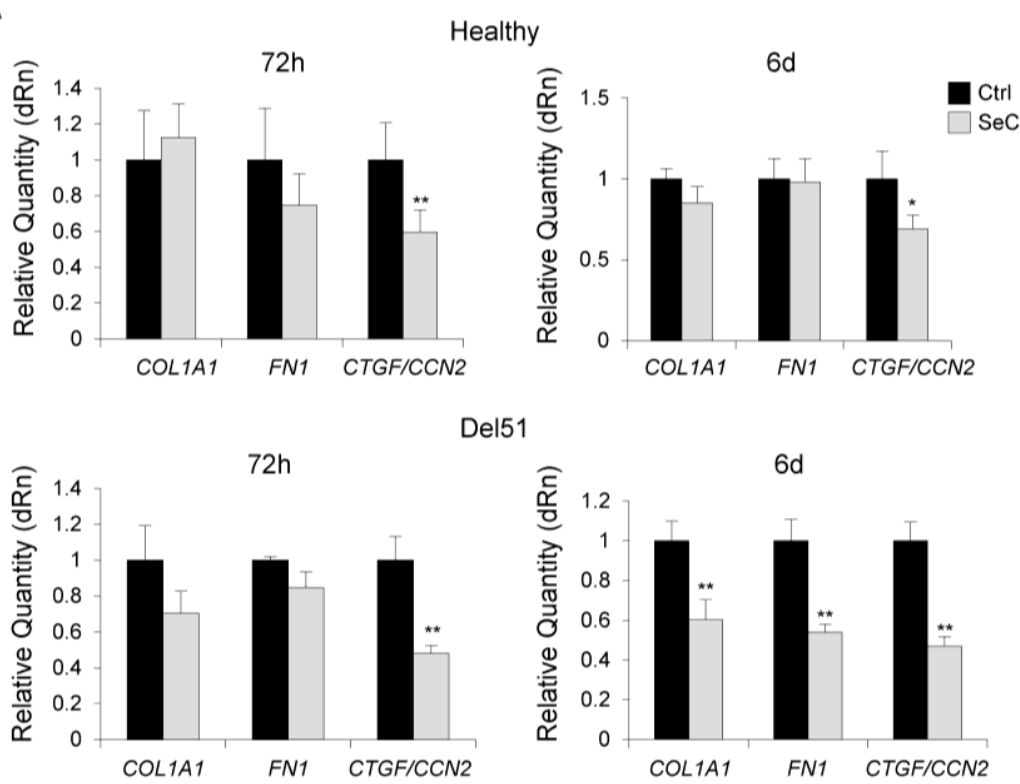

B

WI-38, 24h $\mathbf{C}$ Ctrl

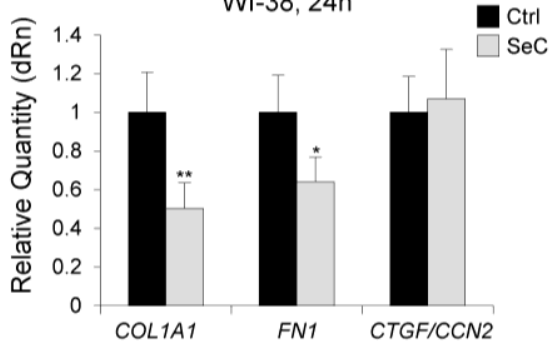

C

$\mathrm{C} 2 \mathrm{C} 12,24 \mathrm{~h}$
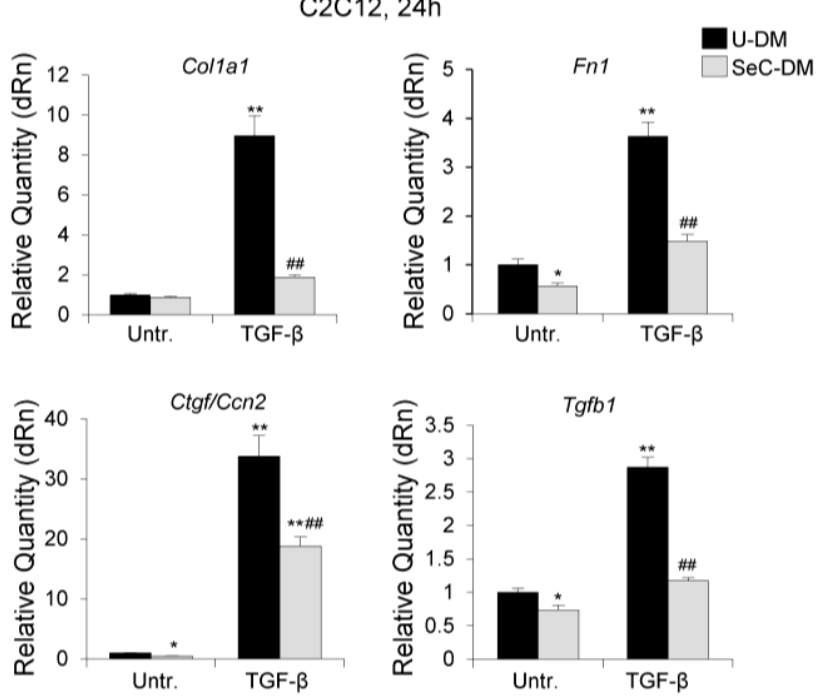

Figure 6. SeC restrain the fibrogenic potential of fibroblasts and inhibit fibrogenic transdifferentiation of myoblasts. (A,B) Human myoblasts derived from healthy donor and Del51 patient (A) or human WI-38 fibroblasts (B) were co-cultured in DM with $(\mathrm{SeC})$ or without (Ctrl) freshly-isolated $\mathrm{SeC}\left(2.0 \times 10^{5} \mathrm{SeC} / \mathrm{mL}\right)$ using $0.4 \mu \mathrm{m}$ BD transwells at the indicated times. Cells were lysed and analyzed for the expression of the fibrogenic markers, COL1A1, FN1, and CTGF/CCN2 by real time-PCR. (C) C2C12 myoblasts cultured in SeC-conditioned (SeC-DM) or unconditioned (U-DM) medium were induced to transdifferentiate into myofibroblasts by treatment with TGF- $\beta(5 \mathrm{ng} / \mathrm{mL})$ for $24 \mathrm{~h}$. Cells were lysed and analyzed for the expression of Col1a1, Fn1, Ctgf /Ccn2, and Tgfb1 by real time-PCR. Reported are the means ( \pm SD) of three independent experiments with respect to control (Ctrl) normalized for GAPDH (A,B) or Gapdh (C) used as house-keeping genes. * and **, significantly different from Ctrl or untreated U-DM (Untr.) ( $p<0.05$ and $p<0.01$, respectively); \#\#, significantly different from TGF- $\beta$-treated U-DM $(p<0.01)$. 
A

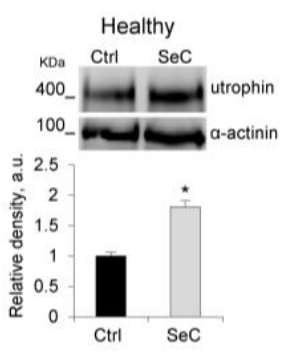

Del51

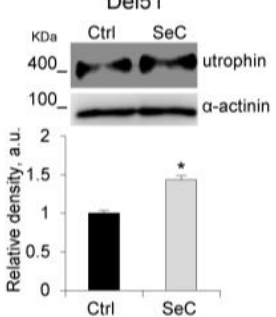

C

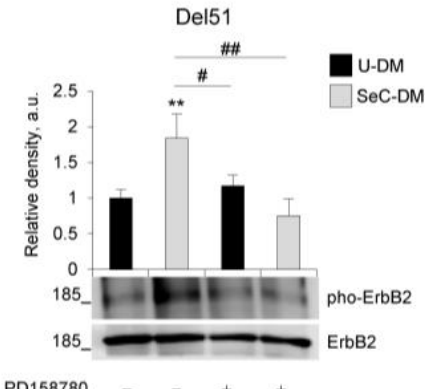

PD158780

E

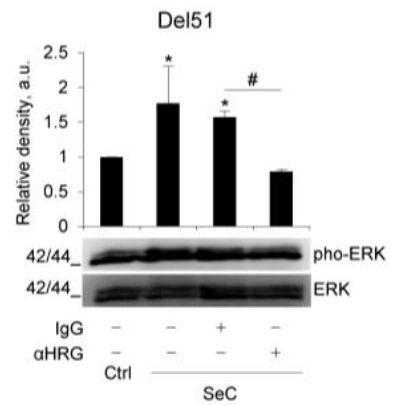

B
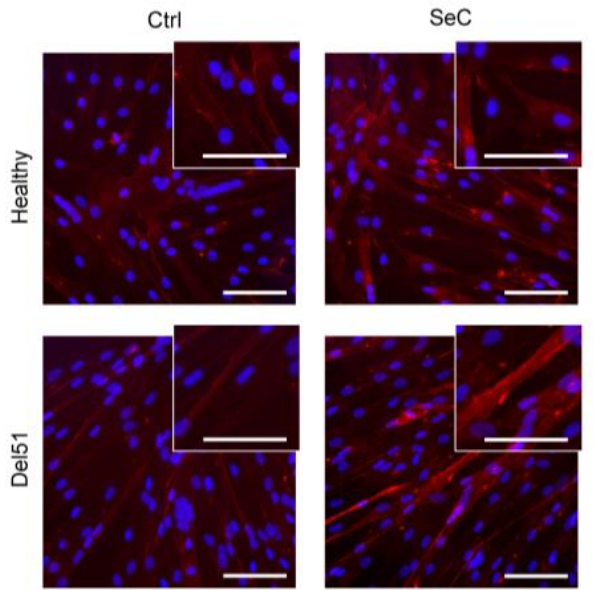

D

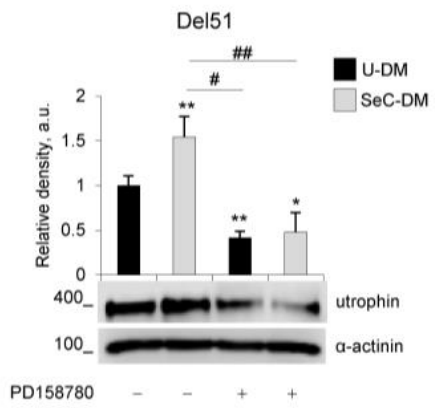

F

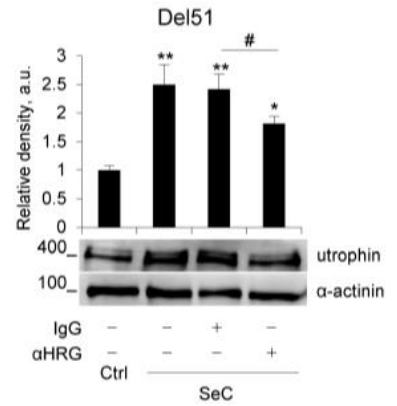

Figure 7. SeC up-regulate utrophin expression in human healthy and DMD myotubes. (A-F) Human myotubes obtained by culturing myoblasts derived from healthy donor or Del51 patient in differentiation medium for 4 days were co-cultured in the absence (Ctrl) or presence of $\mathrm{SeC}\left(2.0 \times 10^{5} \mathrm{SeC} / \mathrm{mL}\right)$ using $0.4 \mu \mathrm{m}$ transwells $(\mathbf{A}, \mathbf{B}, \mathbf{E}, \mathbf{F})$, or cultured in SeC-conditioned (SeC-DM) or unconditioned (U-DM) differentiation medium (C,D). (A) After 48 h, myotubes were lysed and analyzed for utrophin expression by WB. The average relative densities of utrophin bands with respect to $\alpha$-actinin bands are reported. (B) Immunofluorescence analysis for utrophin (red) expression was performed at $48 \mathrm{~h}$, and DAPI (blue) was used to counterstain nuclei. (C,D) Myotubes were cultured with SeC-DM or U-DM for $24 \mathrm{~h}$ in the absence or presence of the ErbB receptor tyrosine kinase inhibitor, PD158780 (100 nM) or the same amounts of vehicle (DMSO). Myotubes were lysed and utrophin (C) and phosphorylated ErbB2 (pho-ErbB2) (D) expression were analyzed by WB. The average relative densities of utrophin and pho-ErbB2 bands with respect to $\alpha$-actinin or total ErbB2 bands, respectively, are reported. (E,F) Myotubes co-cultured with or without SeC were added with either an anti-heregulin $\beta 1$ blocking antibody ( $\alpha \mathrm{HRG}$, $2 \mu \mathrm{g} / \mathrm{mL}$ ) or the same amounts of non-immune IgG to the upper chamber of the transwells for $24 \mathrm{~h}$ (E) or $48 \mathrm{~h}$ (F). Myotubes were lysed and phosphorylated ERK1/2 (pho-ERK) (E) and utrophin (F) expression were analyzed by WB. The average relative densities of pho-ERK and utrophin bands with respect to total ERK or $\alpha$-actinin bands, respectively, are reported. * and ${ }^{* *}$, significantly different from Ctrl or untreated U-DM ( $p<0.05$ and $p<0.01$, respectively). \# and \#\#, significantly different $(p<0.05$ and $p<0.01$, respectively). Reported are representative images (A-F). Results are means $( \pm \mathrm{SD})$ of three independent experiments. Scale bars (B), $50 \mu \mathrm{m}$. 
Del51 myotubes were further investigated for the dependence of utrophin induction by SeC-secreted heregulin $\beta 1$. We found that SeC-DM induced tyrosine phosphorylation of ErbB2 receptor (Figure 7C), whose heterodimerization with ErbB3 is induced by heregulin $\beta 1$ leading to receptor tyrosine phosphorylation and activation of downstream signal transduction [24], and induction of utrophin expression (Figure 7D). Both ErbB2 phosphorylation and utrophin induction were abrogated by the use of PD158780, a potent cell-permeable ErbB receptor tyrosine kinase inhibitor (Figure 7C,D). Moreover, the induction of utrophin was accompanied by activation (phosphorylation) of ERK1/2 MAPKs (Figure 7E), and the use of an anti-heregulin $\beta 1$ antibody hampered the ability of SeC to induce utrophin expression (Figure 7F), and completely abolished the SeC-induced phosphorylation of ERK1/2 MAPKs (Figure 7E). Altogether, these data suggest that similar mechanisms to those reported in mice [12] underpin the SeC-dependent induction of utrophin in human myotubes.

\section{Discussion}

Sertoli cells $(\mathrm{SeC})$ continue to unravel their peculiar effects on a growing number of physiological and pathological conditions $[16,25]$. In addition to their role in creating a physical barrier in the testes necessary for spermatogenesis, $\mathrm{SeC}$ secrete a plethora of factors with trophic and anti-inflammatory effects that have prompted researchers to evaluate the beneficial use of these cells in many pre-clinical models of diseases. Depending on the experimental model investigated, $\mathrm{SeC}$ have shown the ability to protect allogeneic or xenogeneic grafts from immune rejection, or to reduce local inflammation $[14,16,26]$. Animal models of type 1 or type 2 diabetes, Laron syndrome (dwarfism), Huntington's disease, and others, have been reported to take advantage of the injection of naked or microencapsulated (MC-) SeC [14,25,27-30].

Duchenne muscular dystrophy (DMD) is a lethal genetic disease characterized by progressive muscle degeneration due to lack of functional dystrophin. DMD muscles are characterized by continuous necrosis of myofibers leading to a persistent inflammatory state, and loss of muscle mass and strength due to the accumulation of fibrotic and adipose tissues over time $[3,31]$. The $D M D$ gene is the largest human gene $(2.4 \mathrm{Mb})$, including 79 exons and representing $0.08 \%$ of the human genome. The very large size of the $D M D$ gene and the limited homing to muscles demonstrated by ex vivo corrected cells represent the major obstacles encountered by gene- and cell-based therapeutic approaches, respectively [8,32-34]. Another problem is represented by the need of immunosuppression in most proposed approaches to DMD, including therapies with antisense oligonucleotides (AONs), which have also the limitation of being useful only for specific DMD mutations [3,34]. Despite a huge effort in finding a cure, the therapeutic approaches to DMD proposed so far have resulted unsatisfactory in terms of functional recovery, leading to the idea that a combinatorial approach is needed.

MC-SeC injected into the peritoneal cavity of dystrophic $(m d x)$ mice proved to be beneficial in recovering muscle homeostasis thanks to the release of a cocktail of factors that counteract muscle inflammation and fibrosis, and the induction of the expression of the dystrophin paralogue, utrophin at the sarcolemma of myofibers [11,12]. However, data about the effects of $\mathrm{SeC}$ on satellite cells (i.e., the adult stem cells of skeletal muscle residing between the basal lamina and the plasmalemma [35]) and their progeny, the myoblasts, were not available. Here, we demonstrate that $\mathrm{SeC}$ have direct effects on myoblasts, sustaining their proliferation (and inhibiting ROS production and the apoptotic events in the case of $\mathrm{C} 2 \mathrm{C} 12$ myoblasts) in the early phase of the differentiation process. Concomitantly, $\mathrm{SeC}$ do not affect (in the case of healthy human myoblasts) or even improve (in the case of $\mathrm{C} 2 \mathrm{C} 12$ and DMD myoblasts) the myogenic terminal differentiation. The improved differentiation capability observed in the presence of $\mathrm{SeC}$ might be, at least in part, the result of increased myoblast survival favoring the achievement of the critical cell mass necessary to give rise to cell fusion and differentiation. 
The effect in increasing cell numbers is of particular importance when looking at DMD patients, in which a progressive emptying of the satellite cell pool occurs as an outcome of the pathology due to the continuous degeneration/regeneration cycles, leading to defective muscle repair and favoring fibrotic and adipose tissue accumulation $[6,36]$. Incidentally, our data suggest that SeC-based approaches might be useful in improving the early phase of muscle regeneration, during which myoblasts have to adequately proliferate to replace the damaged muscle mass [37].

Noteworthy, the most relevant effect of SeC in improving myogenic differentiation was seen in DMD myoblasts. Contrary to healthy myoblasts, an inability to upregulate $M Y H 2$ transcript levels at day 6 in DM emerged in Del51 myoblasts in basal conditions; however, this was rescued by the presence of $\mathrm{SeC}$, which elicited a three-fold upregulation of $M Y H 2$ expression together with a dramatic increase in MyHC-II protein amounts (Figure 5A,B). This is another interesting effect in consideration of an application of SeC-based treatments to DMD patients.

Several factors known to be secreted by SeC $[8,16]$ might participate to the effects we observed on myoblast proliferation and differentiation. They include, but are not limited to, bFGF (basic fibroblast growth factor) [38], BMP (bone morphogenetic protein) [39], IGFs (insulin-like growth factors) [40], EGF (epidermal-derived growth factor) [41,42], prosaposin [43], and TGF- $\beta$ [44]. The precise combination of these factors, together with other (also still unknown) factors secreted by $\mathrm{SeC}$, is the responsible of the effects exerted by SeC on healthy and DMD myoblasts.

Fibrosis is a typical hallmark of DMD muscles, and it is mainly linked to excess expression and activity of TGF- $\beta$ [23]. Transdifferentiation of myogenic cells into myofibroblasts appears to contribute to the development of fibrosis in injured muscles [45]. We found that during the myogenic differentiation process $\mathrm{SeC}$ restrain the expression of fibrogenic markers, especially CTGF/CCN2, a cytokine synthesized by myoblasts and myotubes in response to TGF- $\beta$ and responsible for TGF- $\beta$ fibrotic activity through increased expression of COL1A1 [46]. This represents a paradigm of the activity of SeC, which despite secreting TGF- $\beta[16,26]$ exert an overall antifibrotic effect as a resultant of the cocktail of factors secreted. This was particularly stressed by the results obtained with $\mathrm{C} 2 \mathrm{C} 12$ myoblasts showing that $\mathrm{SeC}$ are even able to counteract the activity of exogenously administered fibrogenic doses of TGF- $\beta$. The SeC-dependent reduction of CTGF/CCN2 levels might be also functional to improve the myogenic potential since CTGF/CCN2 has been reported to partially inhibit skeletal muscle differentiation and dedifferentiate committed myoblasts [47]. Moreover, our data show that $\mathrm{SeC}$ are able to restrain the fibrogenic potential of fibroblasts, thus revealing another property of SeC useful in counteracting fibrosis in DMD muscles.

In our experimentation, we found that the use of SeC-conditioned medium (SeC-DM) gave very similar results to freshly-isolated $\mathrm{SeC}$ in terms of increased cell numbers and improved myogenic differentiation, in both C2C12 and human myoblasts. However, in comparison with SeC-DM, freshly-isolated SeC exerted a more pronounced promitogenic effect and slightly delayed the appearance of differentiation markers (at $24 \mathrm{~h}$ in DM), although culminating in improved muscle differentiation at $72 \mathrm{~h}$ (data not shown). Thus, treatments centered on acellular SeC derivatives can be envisaged to overcome ethical issues linked to the use of living cells. Since extracellular vesicles have been reported as having a crucial role in intercellular communication through incorporation of their cargo into target cells, regulating a multitude of physiological and pathological processes [48], future studies should investigate the therapeutic potential of SeC-derived extracellular vesicles.

Due to its large size, the $D M D$ gene is particularly susceptible to spontaneous mutations. About 7000 different DMD mutations have been reported, $90 \%$ of which translate into disruption of the open reading frame with appearance of the Duchenne phenotype [49]. Re-expression of utrophin is one of the investigated universal (i.e., suitable regardless of the mutation) approaches to treat DMD muscles since utrophin can serve as a surrogate for dystrophin due to functional redundancy between these two proteins. Indeed, utrophin is able to recruit at the plasmalemma a UAPC that shares members with the dystrophin-associated 
protein complex (DAPC) recruited by dystrophin in normal conditions, and exerts similar protective functions [50]. Our results show that $\mathrm{SeC}$ are able to induce utrophin expression in human DMD myotubes with different mutations, with a mechanism driven by porcine heregulin $\beta 1$, and involving ErbB2 and ERK1/2 MAPK phosphorylation. As reported for $m d x$ mice [12], SeC-induced utrophin is sufficient to recruit members of the UAPC at the periphery of human DMD myotubes, pointing to a functional replacement of the missing dystrophin.

Through activation of ErbB2, SeC-derived heregulin $\beta 1$ might concur also to the observed increased numbers of myoblasts since it has been reported that muscle-specific ErbB2 knockout mice show defects in muscle repair due to decreased myoblast viability during the differentiation process [51].

Together with the reported secretion of trophic and anti-inflammatory factors by $\mathrm{SeC}$ in dystrophic mice $[11,12]$ and no need of immunosuppression typical of SeC-based treatments $[12,16,26-30]$, the current data support a potential use of $\mathrm{SeC}$ as universal (i.e., mutation-independent) approach to DMD. Indeed, we show here that $\mathrm{SeC}$ (i) stimulate the proliferation and subsequent terminal differentiation of dystrophic myoblasts; (ii) restrain the fibrogenic potential of fibroblasts, and reduce myoblast-myofibroblast transdifferentiation; and, (iii) induce utrophin expression in myotubes/myofibers irrespective of the DMD mutation.

This is an in vitro study on a murine cell line and a limited number of humanderived healthy and DMD myoblasts that expands an in vivo study in an animal model of DMD $[11,12]$. The SeC secretory activity results in the production of a cocktail of factors whose formulation is difficult to dissect, the overall effect being not necessarily the sum of the biological effects of single factors $[8,25,26]$. The identification of a minimal cocktail of factors able to mimic the reported effects of $\mathrm{SeC}$ on myoblasts/myotubes should be the aim of further studies.

Supplementary Materials: The following are available online at https:/ /www.mdpi.com/article/ 10.3390/biom11101504/s1, Figure S1: SeC promote early cell proliferation and late terminal differentiation in human healthy and DMD myoblasts, Figure S2: SeC up-regulate utrophin expression in DMD myotubes, Figure S3: $\alpha$-Dystroglycan is recruited at the periphery of healthy and DMD myotubes co-cultured with SeC.

Author Contributions: Conceptualization, L.S. and S.C.; Investigation, L.S., S.C., I.A., F.M., M.C. and M.C.M.; Validation, L.S., S.C., I.A. and F.M.; Formal analysis, L.S. and S.C.; Visualization, L.S., S.C. and F.R.; Resources, I.A., F.M. and M.C.; Writing-Original Draft, L.S., S.C. and G.S.; Writing-Review and Editing, F.R., R.C., G.L. and G.S.; Supervision, G.L. and G.S.; Project administration, G.L. and G.S.; Funding acquisition, R.C., G.L. and G.S. All authors have read and agreed to the published version of the manuscript.

Funding: This research was funded by Parent Project aps (Italy) to G.S., and Altucell Inc. (Dix Hills, NY, USA) to G.L. and R.C.; S.C. and L.S. were recipient of a fellowship granted by Parent Project aps (Italy).

Institutional Review Board Statement: Not applicable.

Informed Consent Statement: Not applicable.

Data Availability Statement: No new data were created or analyzed in this study. Data sharing is not applicable to this article.

Acknowledgments: Biobank of Cells, tissues and DNA from patients with neuromuscular diseases, member of the Telethon Network of Genetic Biobanks (project \#GTB12001), funded by Telethon Italy, the EuroBioBank network, and the Myobank-AFM of the Institut de Myologie (\#BB-0033-0012) provided us with normal and DMD myoblasts.

Conflicts of Interest: The authors declare no conflict of interest. The funders had no role in the design of the study; in the collection, analyses, or interpretation of data; in the writing of the manuscript, or in the decision to publish the results. 


\section{Appendix A}

Table A1. Key resources table.

\begin{tabular}{|c|c|c|}
\hline Reagent or Resource & Source & Identifier \\
\hline \multicolumn{3}{|c|}{ Antibodies } \\
\hline $\begin{array}{c}\text { Donkey anti-Mouse IgG }(\mathrm{H}+\mathrm{L}) \text {, Alexa Fluor } 488 \\
\text { conjugated }\end{array}$ & Thermo Fisher Scientific & Cat\#A-21202 \\
\hline $\begin{array}{c}\text { Donkey anti-Mouse IgG (H + L), Alexa Fluor } 594 \\
\text { conjugated }\end{array}$ & Thermo Fisher Scientific & Cat\#A-21203 \\
\hline Goat anti-mouse IgG/IgM-HRP conjugated & Merck & Cat\#AP130P \\
\hline Goat anti-rabbit IgG-HRP conjugated & Sigma-Aldrich & Cat\#A9169 \\
\hline IgG from rabbit serum & Sigma-Aldrich & Cat\#I5006 \\
\hline Mouse monoclonal anti- $\alpha$-Dystroglycan (IIH6) & Santa Cruz Biotechnology & Cat\# sc-53987 \\
\hline Mouse monoclonal anti-Myogenin (F5D) & Santa Cruz Biotechnology & Cat\#sc-12735 \\
\hline Mouse monoclonal anti-Utrophin (8A4) & Santa Cruz Biotechnology & Cat\#sc-33700 \\
\hline Mouse monoclonal anti- $\alpha$-Actinin (H-2) & Santa Cruz Biotechnology & Cat\#sc-17829 \\
\hline Mouse monoclonal anti- $\alpha$-Tubulin (DM1A) & Santa Cruz Biotechnology & Cat\#sc-32293 \\
\hline Rabbit polyclonal anti-HER2/ErbB2 & Cell Signaling Tech & Cat\#2242 \\
\hline Rabbit polyclonal anti-Heregulin-beta1 & ProSci & Cat\#38-254 \\
\hline Rabbit polyclonal anti-MAP Kinase (ERK-1, ERK-2) & Cell Signaling Tech & Cat\#M5670 \\
\hline $\begin{array}{c}\text { Rabbit polyclonal anti-phospho-ErbB2 (HER-2) } \\
\text { (Tyr877) }\end{array}$ & Invitrogen & Cat\#PA5-77970 \\
\hline $\begin{array}{c}\text { Rabbit polyclonal anti-phospho-p44/42 MAPK } \\
\text { (Erk1/2) (Thr202/Tyr204) }\end{array}$ & Cell Signaling Tech & Cat\#9101S \\
\hline \multicolumn{3}{|c|}{ Chemicals, Peptides, and Recombinant Proteins } \\
\hline Blotto, non-fat dried milk & Santa Cruz Biotechnology & Cat\#sc-2325 \\
\hline Bovine Serum Albumin (BSA) & Sigma-Aldrich & Cat\#A7030 \\
\hline DAPI dihydrochloride & Sigma-Aldrich & Cat\#D9542 \\
\hline DCFH-DA (2', $7^{\prime}$-Dichlorofluorescin diacetate $)$ & Sigma-Aldrich & Cat\#D6883 \\
\hline DMSO (Dimethyl sulfoxide) & Sigma-Aldrich & Cat\#67-68-5 \\
\hline Gelatin solution & Sigma-Aldrich & Cat\#G1393 \\
\hline Giemsa stain, modified & Sigma-Aldrich & Cat\#GS500 \\
\hline May-Grünwald stain & Sigma-Aldrich & Cat\#MG500 \\
\hline PD 158780 tyrosine kinase inhibitor & Santa Cruz Biotechnology & $\begin{array}{c}\text { Cat\#CAS } \\
171179-06-9\end{array}$ \\
\hline Propidium iodide & Sigma-Aldrich & Cat\#81845 \\
\hline Recombinant human TGF- $\beta$ & R\&D System & Cat\#240-B \\
\hline TRIsure ${ }^{\mathrm{TM}}$ & Bioline & Cat\#BIO-38033 \\
\hline Western Bright Quantum HRP substrate & Advansta & $\begin{array}{l}\text { Cat\#K-12042- } \\
\text { D20 }\end{array}$ \\
\hline \multicolumn{3}{|c|}{ Experimental Models: Cell Lines } \\
\hline $\mathrm{C} 2 \mathrm{C} 12$ mouse myoblasts & $\begin{array}{l}\text { ATCC, American Type } \\
\text { Culture Collection }\end{array}$ & Cat\#CRL-1772 \\
\hline WI-38 human fibroblasts & $\begin{array}{l}\text { ATCC, American Type } \\
\text { Culture Collection }\end{array}$ & Cat\#CCL-75 \\
\hline \multicolumn{3}{|c|}{ Culture Medium } \\
\hline Apo-Transferrin human & Sigma-Aldrich & Cat\#T1147 \\
\hline Collagenase $\mathrm{P}$ & Sigma Aldrich & Cat\#11213865001 \\
\hline DNase I & Sigma Aldrich & Cat \#SLCB2343 \\
\hline Fetal bovine serum (FBS) & Gibco & Cat\#10270-106 \\
\hline Gentamicin $10 \mathrm{mg} / \mathrm{mL}$ sulphate & Euroclone & Cat\#ECM0011B \\
\hline HAM'S F12 & Euroclone & Cat\#AL025A \\
\hline
\end{tabular}


Table A1. Cont.

\begin{tabular}{|c|c|c|}
\hline Reagent or Resource & Source & Identifier \\
\hline $\begin{array}{l}\text { High-glucose Dulbecco's Modified Eagle's Medium } \\
\text { (HG-DMEM) }\end{array}$ & Gibco & Cat\#41966-029 \\
\hline Horse Serum (HS) & Gibco & Cat\#16050-122 \\
\hline Insulin solution from bovine pancreas & Sigma-Aldrich & Cat\#I0516-5ML \\
\hline Insulin-Transferrin-Selenium (ITS) + Premix & Corning & Cat\#354352 \\
\hline L-Glutamine $100 \times(200 \mathrm{mM})$ & Euroclone & Cat\#ECB3000D \\
\hline Penicillin/Streptomicin $100 \times$ & Euroclone & Cat\#CB3001D \\
\hline Retinoic acid & Sigma-Aldrich & Cat\#R-2625100 \\
\hline RPMI Medium 1640 & Gibco & Cat\#21875-034 \\
\hline $\begin{array}{l}\text { Skeletal Muscle Cell Growth Medium (ready-to-use } \\
\text { kit) }\end{array}$ & Promo Cell & Cat\#39365 \\
\hline Trypsin $(2.5 \%)$ & Gibco & Cat\#15090-046 \\
\hline \multicolumn{3}{|c|}{ Oligonucleotides } \\
\hline Primers (see Appendix B) & Invitrogen & $\mathrm{N} / \mathrm{A}$ \\
\hline \multicolumn{3}{|c|}{ Software and Algorithms } \\
\hline IBM $^{\circledR}$ SPSS $^{\circledR}$ Statistics v18 software & SPSS (Chicago, IL, USA) & \\
\hline Image Studio Digits v3.1.4 & LI-COR & \\
\hline ImageJ v1.8.0_172 & Wayne Rasband (NIH, USA) & \\
\hline LAS (Leica Application Suite) software v4.12.0 & LEICA & \\
\hline MxPro-Mx3000P v4.10 & $\begin{array}{l}\text { Agilent Technologies } \\
\text { Stratagene }\end{array}$ & \\
\hline SPOT Imaging v3.5.4 & Diagnostic Instruments & \\
\hline \multicolumn{3}{|c|}{ Other } \\
\hline Annexin V-FITC apoptosis detection kit & BioVision Inc. & K101-100 \\
\hline $5 \times$ HOT FIREPol EvaGreen qPCR Mix Plus (ROX) & Solis BioDyne & $08-24-0000$ \\
\hline PrimeScript ${ }^{\mathrm{TM}}$ RT reagent Kit with gDNA Eraser & Takara Bio Europe & RR047B \\
\hline
\end{tabular}

\section{Appendix B}

Table A2. List of primary and secondary antibodies used in Western blotting.

\begin{tabular}{ccccc}
\hline Primary Antibody & $\begin{array}{c}\text { Molecular } \\
\text { Weight (kDa) }\end{array}$ & Dilution & Secondary Antibody & Dilution \\
\hline $\begin{array}{c}\text { Mouse monoclonal } \\
\text { anti-MyHC-II (MF20) }\end{array}$ & 220 & $1: 10,000$ & $\begin{array}{c}\text { Goat anti-mouse } \\
\text { IgG/IgM-HRP conjugated }\end{array}$ & $1: 10,000$ \\
\hline $\begin{array}{c}\text { Mouse monoclonal } \\
\text { anti-myogenin (F5D) }\end{array}$ & 34 & $1: 1000$ & $\begin{array}{c}\text { Goat anti-mouse } \\
\text { IgG/IgM-HRP conjugated }\end{array}$ & $1: 1000$ \\
\hline $\begin{array}{c}\text { Mouse monoclonal anti-Neu } \\
\text { (ErbB2) (3B5) }\end{array}$ & 185 & $1: 200$ & $\begin{array}{c}\text { Goat anti-mouse } \\
\text { IgG/IgM-HRP conjugated }\end{array}$ & $1: 1000$ \\
\hline $\begin{array}{c}\text { Mouse monoclonal } \\
\text { anti-utrophin (8A4) }\end{array}$ & 400 & $1: 1000$ & $\begin{array}{c}\text { Goat anti-mouse } \\
\text { IgG/IgM-HRP conjugated }\end{array}$ & $1: 1000$ \\
\hline $\begin{array}{c}\text { Mouse monoclonal } \\
\text { anti- } \alpha \text {-actinin (H-2) }\end{array}$ & 100 & $1: 5000$ & $\begin{array}{c}\text { Goat anti-mouse } \\
\text { IgG/IgM-HRP conjugated }\end{array}$ & $1: 5000$ \\
\hline $\begin{array}{c}\text { Mouse monoclonal } \\
\text { anti- } \alpha \text {-tubulin (DM1A) }\end{array}$ & 55 & $1: 5000$ & $\begin{array}{c}\text { Goat anti-mouse } \\
\text { IgG/IgM-HRP conjugated }\end{array}$ & $1: 5000$ \\
\hline $\begin{array}{c}\text { Rabbit polyclonal anti-MAP } \\
\text { kinase (ERK1, ERK2) }\end{array}$ & $42-44$ & $1: 10,000$ & $\begin{array}{c}\text { Goat anti-rabbit IgG-HRP } \\
\text { conjugated }\end{array}$ & $1: 10,000$ \\
\hline $\begin{array}{c}\text { Rabbit polyclonal } \\
\text { anti-phospho-ErbB2 (HER-2) } \\
\text { (Tyr877) }\end{array}$ & 185 & $1: 500$ & $\begin{array}{c}\text { Goat anti-rabbit IgG-HRP } \\
\text { conjugated }\end{array}$ & $1: 2000$ \\
\hline $\begin{array}{c}\text { Rabbit polyclonal } \\
\text { anti-phospho-p44/42 MAPK } \\
\text { (ERK1/2) (Thr202/Tyr204) }\end{array}$ & $42-44$ & $1: 1000$ & $\begin{array}{c}\text { Goat anti-rabbit IgG-HRP } \\
\text { conjugated }\end{array}$ & $1: 2000$ \\
\hline
\end{tabular}




\section{Appendix C}

Table A3. List of primers used in real-time PCR.

\begin{tabular}{|c|c|c|}
\hline Gene & Forward Primer 5'-3' & Reverse Primer 5'-3' \\
\hline COL1A1 & TCTGCGACAACGGCAAGGTG & GACGCCGGTGGTTTCTTGGT \\
\hline CTGF/CCN2 & CTTGCGAAGCTGACCTGGAAGA & CCGTCGGTACATACTCCACAGA \\
\hline FN1 & ACAACACCGAGGTGACTGAGAC & GGACACAACGATGCTTCCTGAG \\
\hline GAPDH & AAGAAGGTGGTGAAGCAGG & GTCAAAGGTGGAGGAGTGG \\
\hline MYH2 & CAGCTACTGCACACCCAGAA & CTTCACGGTCTGCTCCATGT \\
\hline Col1a1 & TCATCGTGGCTTCTCTGGTC & GACCGTTGAGTCCGTCTTTG \\
\hline Ctgf/Ccn2 & GCCTACCGACTGGAAGACAC & GTAACTCGGGTGGAGATGCC \\
\hline$F n 1$ & GAAGACAGATGAGCTTCCCCA & GGTTGGTGATGAAGGGGGTC \\
\hline Gapdh & GCCTTCCGTGTTCCTACCC & CAGTGGGCCCTCAGATGC \\
\hline$T g f b 1$ & GCCTGAGTGGCTGTCTTTTGA & CACAAGAGCAGTGAGCGCTGAA \\
\hline
\end{tabular}

\section{References}

1. Emery, A.E. Population frequencies of inherited neuromuscular diseases-A world survey. Neuromuscul. Disord. 1991, 1, 19-29. [CrossRef]

2. Mendell, J.R.; Shilling, C.; Leslie, N.D.; Flanigan, K.M.; al-Dahhak, R.; Gastier-Foster, J.; Kneile, K.; Dunn, D.M.; Duval, B.; Aoyagi, A.; et al. Evidence-based path to newborn screening for Duchenne muscular dystrophy. Ann. Neurol. 2012, 71, 304-313. [CrossRef]

3. Duan, D.; Goemans, N.; Takeda, S.; Mercuri, E.; Aartsma-Rus, A. Duchenne muscular dystrophy. Nat. Rev. Dis. Prim. 2021, 7, 13. [CrossRef] [PubMed]

4. McGreevy, J.W.; Hakim, C.H.; McIntosh, M.A.; Duan, D. Animal models of Duchenne muscular dystrophy: From basic mechanisms to gene therapy. Dis. Model Mech. 2015, 8, 195-213. [CrossRef] [PubMed]

5. Tidball, J.G.; Welc, S.S.; Wehling-Henricks, M. Immunobiology of Inherited Muscular Dystrophies. Compr. Physiol. 2018, 8, 1313-1356. [CrossRef] [PubMed]

6. Bello, L.; Pegoraro, E. The "Usual Suspects": Genes for Inflammation, Fibrosis, Regeneration, and Muscle Strength Modify Duchenne Muscular Dystrophy. J. Clin. Med. 2019, 8, 649. [CrossRef]

7. Ryder, S.; Leadley, R.M.; Armstrong, N.; Westwood, M.; de Kock, S.; Butt, T.; Jain, M.; Kleijnen, J. The burden, epidemiology, costs and treatment for Duchenne muscular dystrophy: An evidence review. Orphanet J. Rare Dis. 2017, 12, 79. [CrossRef]

8. Chiappalupi, S.; Salvadori, L.; Luca, G.; Riuzzi, F.; Calafiore, R.; Donato, R.; Sorci, G. Do porcine Sertoli cells represent an opportunity for Duchenne muscular dystrophy? Cell Prolif. 2019, 52, e12599. [CrossRef] [PubMed]

9. Verhaart, I.E.C.; Aartsma-Rus, A. Therapeutic developments for Duchenne muscular dystrophy. Nat. Rev. Neurol. 2019, 15, 373-386. [CrossRef]

10. Werneck, L.C.; Lorenzoni, P.J.; Ducci, R.D.; Fustes, O.H.; Kay, C.S.K.; Scola, R.H. Duchenne muscular dystrophy: An historical treatment review. Arq. Neuro-Psiquiatria 2019, 77, 579-589. [CrossRef]

11. Chiappalupi, S.; Luca, G.; Mancuso, F.; Madaro, L.; Fallarino, F.; Nicoletti, C.; Calvitti, M.; Arato, I.; Falabella, G.; Salvadori, L.; et al. Effects of intraperitoneal injection of microencapsulated Sertoli cells on chronic and presymptomatic dystrophic mice. Data Brief 2015, 5, 1015-1021. [CrossRef] [PubMed]

12. Chiappalupi, S.; Luca, G.; Mancuso, F.; Madaro, L.; Fallarino, F.; Nicoletti, C.; Calvitti, M.; Arato, I.; Falabella, G.; Salvadori, L.; et al. Intraperitoneal injection of microencapsulated Sertoli cells restores muscle morphology and performance in dystrophic mice. Biomaterials 2016, 75, 313-326. [CrossRef] [PubMed]

13. Griswold, M.D. 50 years of spermatogenesis: Sertoli cells and their interactions with germ cells. Biol. Reprod. 2018, 99, 87-100. [CrossRef]

14. Mital, P.; Kaur, G.; Dufour, J.M. Immunoprotective sertoli cells: Making allogeneic and xenogeneic transplantation feasible. Reproduction 2010, 139, 495-504. [CrossRef]

15. Kaur, G.; Thompson, L.A.; Dufour, J.M. Sertoli cells-immunological sentinels of spermatogenesis. Semin Cell Dev. Biol. 2014, 30 , 36-44. [CrossRef] [PubMed]

16. Luca, G.; Arato, I.; Sorci, G.; Cameron, D.F.; Hansen, B.C.; Baroni, T.; Donato, R.; White, D.G.J.; Calafiore, R. Sertoli cells for cell transplantation: Pre-clinical studies and future perspectives. Andrology 2018, 6, 385-395. [CrossRef]

17. Chiappalupi, S.; Salvadori, L.; Mancuso, F.; Arato, I.; Calvitti, M.; Riuzzi, F.; Calafiore, R.; Luca, G.; Sorci, G. Microencapsulated Sertoli cells sustain myoblast proliferation without affecting the myogenic potential. In vitro data. Data Brief, submitted.

18. Salvadori, L.; Mandrone, M.; Manenti, T.; Ercolani, C.; Cornioli, L.; Lianza, M.; Tomasi, P.; Chiappalupi, S.; Di Filippo, E.S.; Fulle, S.; et al. Identification of Withania somnifera-Silybum marianum-Trigonella foenum-graecum Formulation as a Nutritional Supplement to Contrast Muscle Atrophy and Sarcopenia. Nutrients 2020, 13, 49. [CrossRef] 
19. Chiappalupi, S.; Sorci, G.; Vukasinovic, A.; Salvadori, L.; Sagheddu, R.; Coletti, D.; Renga, G.; Romani, L.; Donato, R.; Riuzzi, F. Targeting RAGE prevents muscle wasting and prolongs survival in cancer cachexia. J. Cachexia Sarcopenia Muscle 2020, 11, 929-946. [CrossRef]

20. Fidziańska, A.; Goebel, H.H. Human ontogenesis. 3. Cell death in fetal muscle. Acta Neuropathol. 1991, 81, 572-577. [CrossRef]

21. Bier, A.; Berenstein, P.; Kronfeld, N.; Morgoulis, D.; Ziv-Av, A.; Goldstein, H.; Kazimirsky, G.; Cazacu, S.; Meir, R.; Popovtzer, R.; et al. Placenta-derived mesenchymal stromal cells and their exosomes exert therapeutic effects in Duchenne muscular dystrophy. Biomaterials 2018, 174, 67-78. [CrossRef]

22. Li, Y.; Foster, W.; Deasy, B.M.; Chan, Y.; Prisk, V.; Tang, Y.; Cummins, J.; Huard, J. Transforming growth factor-beta1 induces the differentiation of myogenic cells into fibrotic cells in injured skeletal muscle: A key event in muscle fibrogenesis. Am. J. Pathol. 2004, 164, 1007-1019. [CrossRef]

23. Bernasconi, P.; Di Blasi, C.; Mora, M.; Morandi, L.; Galbiati, S.; Confalonieri, P.; Cornelio, F.; Mantegazza, R. Transforming growth factor-beta1 and fibrosis in congenital muscular dystrophies. Neuromuscul. Disord. 1999, 9, 28-33. [CrossRef]

24. Sliwkowski, M.X.; Schaefer, G.; Akita, R.W.; Lofgren, J.A.; Fitzpatrick, V.D.; Nuijens, A.; Fendly, B.M.; Cerione, R.A.; Vandlen, R.L.; Carraway, K.L., III. Coexpression of erbB2 and erbB3 proteins reconstitutes a high affinity receptor for heregulin. J. Biol. Chem. 1994, 269, 14661-14665. [CrossRef]

25. Washburn, R.L.; Hibler, T.; Thompson, L.A.; Kaur, G.; Dufour, J.M. Therapeutic application of Sertoli cells for treatment of various diseases. Semin Cell Dev. Biol. 2021. [CrossRef]

26. Chiappalupi, S.; Salvadori, L.; Luca, G.; Riuzzi, F.; Calafiore, R.; Donato, R.; Sorci, G. Employment of Microencapsulated Sertoli Cells as a New Tool to Treat Duchenne Muscular Dystrophy. J. Funct. Morphol. Kinesiol. 2017, 2, 47. [CrossRef]

27. Fallarino, F.; Luca, G.; Calvitti, M.; Mancuso, F.; Nastruzzi, C.; Fioretti, M.C.; Grohmann, U.; Becchetti, E.; Burgevin, A.; Kratzer, R.; et al. Therapy of experimental type 1 diabetes by isolated Sertoli cell xenografts alone. J. Exp. Med. 2009, 206, 2511-2526. [CrossRef] [PubMed]

28. Luca, G.; Calvitti, M.; Mancuso, F.; Falabella, G.; Arato, I.; Bellucci, C.; List, E.O.; Bellezza, E.; Angeli, G.; Lilli, C.; et al. Reversal of experimental Laron Syndrome by xenotransplantation of microencapsulated porcine Sertoli cells. J. Control Release 2013, 165, 75-81. [CrossRef] [PubMed]

29. Luca, G.; Bellezza, I.; Arato, I.; Di Pardo, A.; Mancuso, F.; Calvitti, M.; Falabella, G.; Bartoli, S.; Maglione, V.; Amico, E.; et al. Terapeutic Potential of Microencapsulated Sertoli Cells in Huntington Disease. CNS Neurosci. Ther. 2016, 22, 686-690. [CrossRef] [PubMed]

30. Luca, G.; Arato, I.; Mancuso, F.; Calvitti, M.; Falabella, G.; Murdolo, G.; Basta, G.; Cameron, D.F.; Hansen, B.C.; Fallarino, F.; et al. Xenograft of microencapsulated Sertoli cells restores glucose homeostasis in $\mathrm{db} / \mathrm{db}$ mice with spontaneous diabetes mellitus. Xenotransplantation 2016, 23, 429-439. [CrossRef] [PubMed]

31. Rosenberg, A.S.; Puig, M.; Nagaraju, K.; Hoffman, E.P.; Villalta, S.A.; Rao, V.A.; Wakefield, L.M.; Woodcock, J. Immune-mediated pathology in Duchenne muscular dystrophy. Sci. Transl. Med. 2015, 7, 299rv4. [CrossRef]

32. Skuk, D.; Tremblay, J.P. Myoblast transplantation: The current status of a potential therapeutic tool for myopathies. J. Muscle Res. Cell. Motil. 2003, 24, 285-300. [CrossRef]

33. Duan, D. Systemic AAV Micro-dystrophin Gene Therapy for Duchenne Muscular Dystrophy. Mol. Ther. 2018, 26, 2337-2356. [CrossRef]

34. Sun, C.; Shen, L.; Zhang, Z.; Xie, X. Therapeutic Strategies for Duchenne Muscular Dystrophy: An Update. Genes 2020, $11,837$. [CrossRef]

35. Yin, H.; Price, F.; Rudnicki, M.A. Satellite cells and the muscle stem cell niche. Physiol. Rev. 2013, 93, 23-67. [CrossRef]

36. Cappellari, O.; Mantuano, P.; De Luca, A. “The Social Network" and Muscular Dystrophies: The Lesson Learnt about the Niche Environment as a Target for Therapeutic Strategies. Cells 2020, 9, 1659. [CrossRef]

37. Chargé, S.B.; Rudnicki, M.A. Cellular and molecular regulation of muscle regeneration. Physiol. Rev. 2004, 84, 209-238. [CrossRef] [PubMed]

38. Riuzzi, F.; Sorci, G.; Donato, R. S100B protein regulates myoblast proliferation and differentiation by activating FGFR1 in a bFGF-dependent manner. J. Cell. Sci. 2011, 124, 2389-2400. [CrossRef]

39. Ono, Y.; Calhabeu, F.; Morgan, J.; Katagiri, T.; Amthor, H.; Zammit, P.S. BMP signalling permits population expansion by preventing premature myogenic differentiation in muscle satellite cells. Cell. Death Differ. 2011, 18, 222-234. [CrossRef] [PubMed]

40. Florini, J.R.; Ewton, D.Z.; Coolican, S.A. Growth hormone and the insulin-like growth factor system in myogenesis. Endocr. Rev. 1996, 17, 481-517. [CrossRef] [PubMed]

41. D'Andrea, P.; Sciancalepore, M.; Veltruska, K.; Lorenzon, P.; Bandiera, A. Epidermal Growth Factor-based adhesion substrates elicit myoblast scattering, proliferation, differentiation and promote satellite cell myogenic activation. Biochim. Biophys. Acta Mol. Cell. Res. 2019, 1866, 504-517. [CrossRef]

42. Wang, Y.X.; Feige, P.; Brun, C.E.; Hekmatnejad, B.; Dumont, N.A.; Renaud, J.M.; Faulkes, S.; Guindon, D.E.; Rudnicki, M.A. EGFR-Aurka Signaling Rescues Polarity and Regeneration Defects in Dystrophin-Deficient Muscle Stem Cells by Increasing Asymmetric Divisions. Cell Stem Cell 2019, 24, 419-432.e6. [CrossRef] [PubMed]

43. Rende, M.; Brizi, E.; Donato, R.; Provenzano, C.; Bruno, R.; Mizisin, A.P.; Garrett, R.S.; Calcutt, N.A.; Campana, W.M.; O’Brien, J.S. Prosaposin is immunolocalized to muscle and prosaptides promote myoblast fusion and attenuate loss of muscle mass after nerve injury. Muscle Nerve 2001, 24, 799-808. [CrossRef] [PubMed] 
44. Melendez, J.; Sieiro, D.; Salgado, D.; Morin, V.; Dejardin, M.J.; Zhou, C.; Mullen, A.C.; Marcelle, C. TGF $\beta$ signalling acts as a molecular brake of myoblast fusion. Nat. Commun. 2021, 12, 749. [CrossRef]

45. Li, Y.; Huard, J. Differentiation of muscle-derived cells into myofibroblasts in injured skeletal muscle. Am. J. Pathol. 2002, 161, 895-907. [CrossRef]

46. Vial, C.; Zúñiga, L.M.; Cabello-Verrugio, C.; Cañón, P.; Fadic, R.; Brandan, E. Skeletal muscle cells express the profibrotic cytokine connective tissue growth factor (CTGF/CCN2), which induces their dedifferentiation. J. Cell Physiol. 2008, 215, 410-421. [CrossRef] [PubMed]

47. Hillege, M.M.G.; Galli Caro, R.A.; Offringa, C.; de Wit, G.M.J.; Jaspers, R.T.; Hoogaars, W.M.H. TGF- $\beta$ Regulates Collagen Type I Expression in Myoblasts and Myotubes via Transient Ctgf and Fgf-2 Expression. Cells 2020, 9, 375. [CrossRef]

48. EL Andaloussi, S.; Mäger, I.; Breakefield, X.O.; Wood, M.J. Extracellular vesicles: Biology and emerging therapeutic opportunities. Nat. Rev. Drug. Discov. 2013, 12, 347-357. [CrossRef]

49. Bladen, C.L.; Salgado, D.; Monges, S.; Foncuberta, M.E.; Kekou, K.; Kosma, K.; Dawkins, H.; Lamont, L.; Roy, A.J.; Chamova, T.; et al. The TREAT-NMD DMD Global Database: Analysis of more than 7,000 Duchenne muscular dystrophy mutations. Hum. Mutat. 2015, 36, 395-402. [CrossRef]

50. Guiraud, S.; Roblin, D.; Kay, D.E. The potential of utrophin modulators for the treatment of Duchenne muscular dystrophy. Expert Opin. Orphan Drugs 2018, 6, 179-192. [CrossRef]

51. Andrechek, E.R.; Hardy, W.R.; Girgis-Gabardo, A.A.; Perry, R.L.; Butler, R.; Graham, F.L.; Kahn, R.C.; Rudnicki, M.A.; Muller, W.J. ErbB2 is required for muscle spindle and myoblast cell survival. Mol. Cell. Biol. 2002, 22, 4714-4722. [CrossRef] 